\title{
A Comprehensive Analysis of Passenger Alighting and Boarding Rates
}

\author{
Nigel G Harris ${ }^{1}\left[\right.$ [ $\cdot$ Flavia de Simone $^{2} \cdot$ Ben Condry $^{2}$
}

Received: 12 April 2021 /Revised: 8 October 2021/Accepted: 14 December 2021/Published online: 7 March 2022

(C) The Author(s) 2022

\begin{abstract}
The understanding and management of station stops continues to be a key issue in the operation of urban railways. This paper reports a statistical meta-analysis of passenger alighting and boarding rates from an expansion of a real-life worldwide data set which includes 34 different variables reflecting characteristics of passenger flow, rolling stock design, infrastructure and management actions. This has enabled the authors to identify, test hypotheses about, and quantify the impact of, previouslyuntested variables. A stepwise regression method using the $\mathrm{R}$ statistical package was proposed and developed into a more tractable model with fewer variables. This process eliminated those variables shown to provide no statistical explanation (including the presence of platform edge doors). Of the remaining 18 hypothesised variables, all provided some form of statistical explanation at the $90 \%$ level (or more) in one model or another. The results will help railways and transport authorities around the world manage station stops, through timetabling and appropriate investment.
\end{abstract}

Keywords Station stops - Passenger alighting and boarding rates $\cdot$ Statistical meta-analysis $\cdot$ Stepwise regression $\cdot$ Key determining variables - Urban railway

Nigel G Harris

nigel.harris@railwayconsultancy.com

1 The Railway Consultancy Ltd, Crystal Palace station, London SE19 2AZ, UK

2 Transport Strategy Centre, Imperial College, London SW7 2AZ, UK

Communicated by Valentina Cacchiani.

\section{Introduction}

In urban areas, which are one of the rail mode's key passenger markets, line capacity is determined not so much by signalling arrangements as by what happens at stations. That time comprises the function/technical time needed for operation, but also the time needed for passenger flow (alighting and boarding), which is the focus of this paper. When railways are busy, line headways can easily be exceeded in track sections which include platforms. Not only is it common for

$t_{\mathrm{p}}+t_{\mathrm{f}}+t_{\mathrm{v}}+\mathrm{RORI}>H$

where $t_{\mathrm{p}}=$ passenger movement time, $t_{\mathrm{f}}=$ fixed function time (e.g. door opening and closing), $t_{\mathrm{v}}=$ variable function time, $\mathrm{RORI}=$ run-out/run-in time (the minimum platform reoccupation time permitted by the signalling), and $H=$ planned service headway, but the variability and potential for delay associated with $t_{\mathrm{p}}$ increases the likelihood of delays in corridors in which high levels of capacity utilisation may prevent easy recovery.

This is clearly a key area of concern for many urban railways, and one in which much effort has already been made, including by the partners reporting this research.

The Railway Consultancy Ltd in UK is a specialist railway planning company who advise on both commercial and operational rail matters. This has led to a number of research papers on both sub-threshold delays (including those arising during station stops) and passenger movement rates, from work undertaken particularly in the UK, Norway and Germany.

The Transport Strategy Centre at Imperial College London is an applied research centre focussed on public transport economics, operations and management. It undertakes, amongst other projects, cross-departmental 
benchmarking between c. 90 companies who operate metro, light rail, suburban rail and national rail services around the world. As part of the operational analysis, however, that includes station stop surveys carried out in a similar style to those originally developed by London Underground (e.g. see [1], a paper which also sets out the context of these surveys, with some early results of different passenger rates). Those have formed the basis for a number of practical research papers establishing best practice for urban railways, including Canavan [2].

This paper is structured as follows: Sect. 2 summarises previous literature from the various main avenues of research, whilst Sect. 3 describes the manner in which data has been assembled for this analysis. Section 4 sets out our analytical method, with Sect. 5 providing the key results. Sect. 6 summarizes the conclusion with a discussion of these results.

\section{Literature Review}

Since the early work of Weston [3], considerable research effort has gone into this important subject. Researchers have generally followed one of four paths, as follows:

(i) those using laboratory-based experiments with volunteers;

(ii) those using data from real-world platform situations;

(iii) those using higher-level statistical analysis from railway performance data; and

(iv) those using simulations.

An interesting omission from this list-so far-is the use of 'big data' automatically collected from passenger counting systems and video monitoring on an ongoing basis.

We do not cover the simulation literature in this paper, not least because it is based on the parameters which the other approaches seek to calculate directly, in a similar manner to which Alvarez et al. [4] have applied Weston's early formula to an entirely new context in Panama.

Several issues, however, are key to understanding the results from all methods. First, it is important to realise that, because movements can occur across many doorways simultaneously, it is only the busiest ('critical') door that is the determinant of $t_{\mathrm{p}}$. There are many practical ways of reducing this (see [5]), and it is the aim of this research to update evidence indicating the relative effectiveness of these. The two areas excluded from the current analysis are the management of the total number of potential passengers per train through different timetable design (frequency, stopping pattern, fares policy, etc.) and the distribution of passengers between doors (recently addressed by [6]).

\subsection{Laboratory Research}

In order to control elements of experimental design as much as possible, some researchers have tried to set up laboratory conditions to mimic the platform-train interface. Daamen et al. [7] reported results on the platformtrain gap and carriage of luggage, from the Stevin laboratory at Delft University.

The main stream of laboratory-based research has, however, been based around University College London (UCL)'s Pedestrian Accessibility and Movement Environment Laboratory (PAMELA) physical train mock-up and subsequent work set up at the University of Los Andes, in Santiago de Chile. Only the briefest summary of that work is included in this section, because the contribution of individual papers is introduced where relevant, in the variable-by-variable specification of possible parameters, which follows in Sect. 3.

Fernandez et al. [8] demonstrated increasing flow rates with increasing passenger density (which, given their definition, broadly equates to the relationships we show with increasing passenger numbers). They also found that flow rates are maximised with a small, as opposed to minimal, (vertical/horizontal) platform-train gap, although this goes against what one might expect from first principles of the understanding of human physiology [9].

\subsection{Research on Operational Railways}

Important contributions to understanding passenger movements on live railways have come from Heinz [9] in Sweden, Wiggenraad [10] and Daamen et al. [7] in the Netherlands, Lam et al. [11] in Hong Kong, and our own work around the world. The Transport Strategy Centre (TSC) has extensive experience in metro railways, especially the larger ones, whilst Railway Consultancy Ltd (RCL)'s work has generally complemented this with work for suburban and mainline railways. Some authors (e.g. Watts et al. 2018) also quote live measurements as part of their calibration for their laboratory research.

\subsection{Statistical Analysis}

Given what train operators know about the train and carriage loadings at/from previous stations along the route, and the relative busyness of stations and times of day, it is possible to provide some guidance about the expected durations of $t_{\mathrm{p}}$ from statistical analysis based on past experience. For instance, Buchmüller et al. [12, Figure 5] clearly show the impact of passenger flow rates increasing with passenger quantities, as part of a wider quantitative assessment of station stop time data derived from automatic train-borne equipment. 
Whilst not providing behavioural explanation, 'passengerdisregarded' aggregate statistical methods such as that by $\mathrm{Li}$ et al. [13] can provide reasonable estimates, which can be particularly useful if station-specific conditions make 'passenger-regarded' models difficult to estimate. Disregarded models (e.g. that of d'Acierno et al. [14] in Naples) can also enable the impact of service bunching to be demonstrated if headways (and hence per-train passenger loads) vary from those planned, which can be helpful. However, our aim was to enable railway operators and authorities to be able to estimate the impact of changes in location-specific characteristics, for which the disregarded models are inadequate.

\subsection{Synthesis}

A key issue particularly with the stream of laboratory research is of trying to examine variables in isolation. Their apparent importance could be misunderstood if correlations with other variables were not also taken into account. To an extent, these problems also occur with research on operational railways since, for instance, some train design features (e.g. longitudinal seating and large vestibules) are usually combined. For real value for those producing rolling stock and operating railways, it would therefore be helpful to be able to provide some form of more comprehensive approach which could put the importance of different factors into perspective.

A meta-analysis of data compiled jointly by RCL and the Railway and Transport Strategy Centre (RTSC) [15] enabled the first predictive model to be constructed, following a regression of 17 different variables.

Analysis based on this model has subsequently been used by RCL to advise clients, both in terms of rolling stock design and also to predict station stop times at specific locations. Unfortunately, the 2014 analysis had a number of weaknesses. For instance, insufficient constraints were used to limit some parameters to known directionality or size.

This current research is therefore designed to:

(i) remove some analytical weaknesses with the 2014 model;

(ii) incorporate some new independent variables which have been hypothesised to impact on passenger movement times; and

(iii) recalculate values based on a larger sample (of 225 , not 125 , surveys).

\section{Data Specification}

In order to ensure the greatest likely level of explanation, this section summarises previous research on each of the independent variables considered. Various authors (e.g.
$[14,16])$ have noted that the potential independent variables here fall into several key categories. These relate to fixed infrastructure, rolling stock, passenger flow and management, are summarised in Table 1 below, and form the basis of the descriptive structure which we have adopted here.

\subsection{Passengers}

\subsubsection{Quantity}

Following the work of Wiggenraad [10], it is important to note the required measurement technique for this: the passenger flows included in this analysis only relate to clustered passengers (those forming a continuous flow), with 'late runners' being excluded.

From first principles, the quantity of passengers would be expected to be a determinant of passenger movement times and rates. However, it is often assumed (e.g. [14, 11, Figure 5]) that there is a linear relationship between the number of passengers and the time taken, but results from RCL and others (e.g. [17, 18]) suggest otherwise (see Fig. 1, with time tapering off at the highest number of passenger movements). Luangloriboon et al. [19] found that passenger boarding rates increased with in-car passenger density, but only up to 3 passengers $/ \mathrm{m}^{2}$, and not thereafter. Heinz [9, p 120] suggests that the linear relationship only applies at door widths greater than $1.8 \mathrm{~m}$, a typical maximum width of a train doorway.

Christoforou et al. [20] calibrated a regression model on light rail traffic in Nantes (France) using the sum of boarding and alighting passengers together, but there are reasons to believe (e.g. the relative amount of space on platforms, compared to within trains) that the rates of movement of the two groups are not likely to be the same.

What d'Acierno et al. [14] did correctly identify, however, was that forecasts of movement rates and dwell times need to be time/train-specific. In the urban area they studied (Napoli, Italy), train capacity may be reached during peak periods, leading to passengers being left behind and therefore increasing the number of passengers requiring the following train. In suburban and mainline railways, a common problem is variations in stopping patterns and destinations, which lead to variable loads between successive trains (as well as passengers on platforms awaiting later trains but blocking the movement of passengers in and out of the current one).

However, even for a given quantity of people, their distribution along the platform and between different train carriages is critical. This was recognised in Weston's original [3] research, in which he used a general peakiness factor to relate the number of passenger movements at the busiest door to those at the average door. At specific 
Table 1 Summary of data available

\begin{tabular}{|c|c|c|}
\hline Context & Passenger variables & Platform variables \\
\hline Type of railway $(\mathrm{F})$ & Number of alighters/boarders & Outside protection (D) \\
\hline Continent $(\mathrm{F})$ & Boarders: alighters (ratio) & $\begin{array}{l}\text { Separate platforms for alighting and boarding } \\
\text { (D) }\end{array}$ \\
\hline City & Alighters $\times$ boarders (product) & Platform screen doors (D) \\
\hline Station & Vestibule load (passengers) & Platform width (m) \\
\hline Platform ID & Vestibule load/capacity (\%) & Average egress distance (m) \\
\hline \multirow[t]{2}{*}{ Survey date } & $\begin{array}{l}\text { Alighters/boarders in excess of remaining vestibule } \\
\text { capacity }\end{array}$ & Vertical step distance (mm) \\
\hline & $\%$ of passengers with luggage & Horizontal step distance (mm) \\
\hline Management variable & & Pythagorean step distance (mm) \\
\hline \multicolumn{3}{|l|}{ Management Quality Index } \\
\hline \multicolumn{3}{|l|}{ Rolling stock variables } \\
\hline $\begin{array}{l}\text { Number of floors (double-deck) } \\
\text { (D) }\end{array}$ & Standback width (m) & Saloon exit difficulty $(\mathrm{F})$ \\
\hline Train steps & Standback width category $(\mathrm{F})$ & Car area $\left(\mathrm{m}^{2}\right)$ \\
\hline Train steps (D) & Grab poles (D) & Car area/door width (m) \\
\hline Doors per car & Vestibule size $\left(\mathrm{m}^{2}\right)$ & Seats per car \\
\hline Inter-door distance (m) & Vestibule capacity (passengers) & $\%$ of seats which are longitudinal \\
\hline Door width (m) & Aisle width at vestibule (m) & No. of seats/train width \\
\hline Door width category $(\mathrm{F})$ & Aisle width in saloon (net of passengers' feet) (m) & Seating density (seats $/ \mathrm{m}^{2}$ ) \\
\hline
\end{tabular}

Dependent variables $=$ alighting/boarding rate per second

$D$ dummy variables

$F$ categorised functions

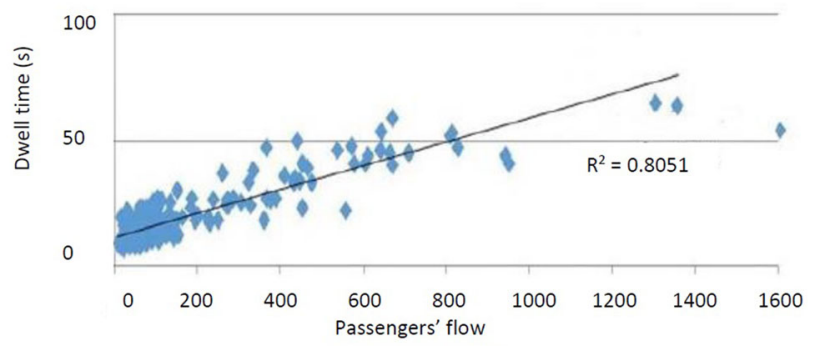

(a) Dwell times vs. passenger' flows in Line A Stations

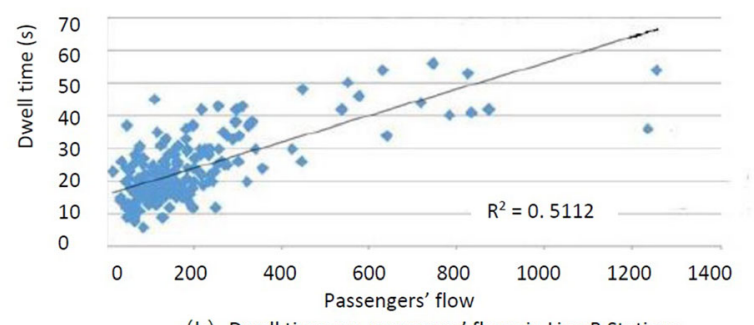

(b) Dwell times vs. passenger' flows in Line B Stations

Fig. 1 Non-linearity of passenger flow by number of passengers. Source: [17]

locations, the exact values can be calculated, as Fox et al. [21] did for Oxford, Britain.

\subsubsection{Passenger Interactions}

In line with the seminal contribution of Fruin [22], one would expect from first principles that crowding hinders pedestrian flow. Indeed, crowding in the vestibules of public transport vehicles has long been recognised as following the traditional $\chi^{2}$ relationships familiar throughout transport planning. For instance, Weidmann [23, p 173] provided some values of the impact of congestion caused by passengers standing on buses. More recently, several authors have specifically analysed this issue. Fernandez [24] provided estimates of decreases in passenger alighting and boarding rates with increasing crowding levels on buses, whilst Palmqvist et al. [25] identified that, in Tokyo, increases in congestion levels of $10 \%$ added about $1 \mathrm{~s}$ to passenger movement times (and hence overall dwell times).

Weston's early work [3] also included an interaction term between the number of boarding and alighting passengers, to reflect the observed pedestrian conflicts. However, Harris [26] noted that this approach over-estimated station stop times at very busy locations (e.g. more than 20 boarders and alighters at the same door), hypothesising that 
the large space vacated by the 20 alighters more easily enabled significant numbers of boarders to do so quickly.

Lee et al. [27], working in Seoul (Korea), identified four different types of situations in which conflicts between boarding, alighting and standing passengers occurred, with different proportions of each resulting from the relevant train door from different platform entry and exit points. Overall passenger movement rates fell from c. 1 passenger/ $\mathrm{s}$ as the number of remaining passengers fell. This is supported by the hypothesis of social pressure, i.e. that where there is room to do so, passenger movement is quicker when individuals feel pressured to hurry by those behind them.

Seriani et al. [28] investigated the impact of the boarding-to-alighting ratio, since one might hypothesise that equal numbers of boarders and alighters provide the maximum conflicting interaction, which a predominantly unidirectional movement would avoid. However, their results were not clear-cut, perhaps reflecting the possibility that a dominant movement of alighters can switch to a dominant movement of boarders at any stage during the station stop.

\subsubsection{Passenger Characteristics}

Wiggenraad [10] disaggregated his results by type of passenger (peak/off-peak), but actually found almost no difference in passenger movement rates; however, passengers on intercity trains were demonstrably $(10-15 \%)$ slower than on local trains, perhaps reflecting variables such as lesser journey familiarity and more luggage, as well as any rolling stock-related factors. In their laboratory-based experiments, Daamen et al. [7] reported reductions in passenger flow rates of around $25 \%$ for participants with luggage. Following a programme of work for several British train operators, Harris and Ehizele [29] isolated the impacts of large luggage on passenger movement rates. Reductions in passenger flow rates ranged between 10 and $83 \%$, depending upon situation-specific circumstances such as the size of the platform-train gap (and probably also the stowage arrangements of luggage within the train, although it was not possible to test that). The higher values appear to be realistic where free flow throughout the alighting or boarding process would otherwise have been possible.

\subsection{Rolling Stock}

\subsubsection{Doors}

Railway managers have understood for some time that increasing the proportion of train length comprised of train doors enables a greater throughput of passengers. This is behind the recent decision in London for Crossrail trains to have three, rather than the British-conventional two, doors per car and the longer-established development of trains with up to five doors per car in the Asian conditions of highest demand in Shanghai and Hong Kong. This can be the single most important element of design to improve passenger flow rates, and the arithmetic is very simple: 50 passengers alighting at 1 passenger/s through two doors take $25 \mathrm{~s}$, but through five doors take only $10 \mathrm{~s}$. However, it is less clear whether movement rates per se are also affected.

A related variable is that of car area/door width, as the total vehicle capacity is a function of car volume not just car length. This attempts to make some adjustment for car width which (in our sample) ranges between 2.34 and $3.6 \mathrm{~m}$.

The distance between doors was previously studied but failed to demonstrate a relationship for boarding, even though it seems plausible that marking platforms to inform passengers about the expected position of train doors would be helpful. However, distance between doors was found to be statistically significant for alighters, presumably reflecting the longer time taken to access doors from more distant locations within the train, and therefore the difficulty in sustaining optimum flow rates throughout this process. This is also relevant to the discussion on aisle widths (see below).

From first principles, it might be thought that increasing the door width of trains improved passenger movement rates. However, this is not a linear relationship. Heinz [9] postulated that rates were a function of $1 / \mathrm{W}^{2}$, whilst Harris et al. [30], based on practical work in Norway and elsewhere, demonstrated that the relationship was not monotonic. Instead, a step function could be seen, corresponding to passengers' ability to pass through a door one at a time, two at a time, or three at a time. This confirmed the hypothesis of Heinz [9, Fig. 31]. The maximum (saturation) flows identified by Fernandez et al. [8] also imply non-linearities, which vary by platform-train gap.

\subsubsection{Vestibules and Standbacks}

Creating more space in vestibules and, in particular, behind the doors (so that passengers not wishing to leave or board the train can keep out of the way of those who do) would be expected to lead to an increase in passenger movement rates. Interestingly, both Harris et al. [15] and Seriani and Fujiyama [16] only managed to isolate an effect for boarding passengers, and even then the impact was relatively small (only around a $3 \%$ rate enhancement per $10-\mathrm{cm}$ increase in the width of the standback).

Understanding that the two variables are often considered jointly by train designers, researchers at UCL [31] undertook one range of experiments attempting to find the optimal sizes of both door widths and standbacks. 
Although only analysed within a narrow range, optimum results from their PAMELA mock-up were for widths of $1.7 \mathrm{~m}$ and standbacks of $0.3 \mathrm{~m}$. Standbacks and vestibule capacity were both previously analysed [15], but we have now developed a new variable relating to the vestibule capacity actually available, by subtracting from the vestibule capacity the number of passengers recorded as remaining within the vestibule during a station stop. Such a variable unfortunately suffers from the variability of on which side of the train the next platform is, and whether those in the vestibule know this.

\subsubsection{Seating Arrangements}

Increasing the circulating space of rolling stock would theoretically be expected to increase passenger movements through it, and this can be achieved by amending seating arrangements. For instance, Coxon et al. [32] noted the potential of longitudinal seating (i.e. that along the vehicle body side only), but did not quote any specific results. Harris et al. [15] included in their overall regression terms for car area, and the \% of seats which were longitudinal, but subsequent data collection enables us to examine other variables. Information on the number of seats per vehicle, together with its area, now enable us to examine the impact of seating density: one might hypothesise that passenger movements take longer within a train space which includes more obstacles (seats).

\subsubsection{Aisle Width}

During field observations, there have been times when passenger flow through the train doors has been freeflowing, but boarders are clearly queuing back from an internal obstruction. Detailed investigation showed that there are many types of rolling stock in which the dimensions of the aperture between vestibule and passenger seating ('saloon') area are smaller than those of the train door. This is the case even in many urban rail fleets where there is no actual door into the saloon.

We have therefore hypothesised that the width of the aisle might affect passenger movement rates, both for boarding (as described above) but also potentially for alighting, since it might reasonably be understood to limit the free flow of passengers towards the train doors.

To our knowledge, there have been no previous attempts to estimate the impact of this parameter. What is less clear a priori is what the nature of the relationship might be. We undertook some preliminary analysis to see if its impact on boarding was directly related to vestibule occupancy, on the basis that the aisle width bottleneck would be expected to become more apparent more quickly when the vestibule already had some standing passengers; however, this did not turn out to be the case. This is perhaps because some passengers will seek out a seat, even if there is plenty of space to stand in the vestibule, whilst others will be prepared to stand, even if seats are readily available.

Whilst recognising the difficulty of estimating the aisle width of train fleets with longitudinal seating (we have made a $30-\mathrm{cm}$ allowance for the feet of passengers on each side of the train), separate variables have been developed for the aisle width at the point of entry from the vestibule, and its average elsewhere. These clearly differ in some types of rolling stock (e.g. see Fig. 2). We have taken the narrowest value of each variable, although it is arguable that aisle width is most critical at hip height, since this is where most humans are widest.

We also tried to develop a variable which might measure the relative difficulty of accessing/exiting the main passenger seating areas. This clearly only applies to passengers actually trying to do so, i.e. those in excess of the number remaining in the vestibule. The 'saloon exit difficulty' variable was therefore defined as:

Number of alighters/boarders - number in the vestibule Aisle width (net of space for feet, where seating is longitudinal)

The variable takes a zero value if the number of alighters/ boarders is less than the capacity of the vestibule, although

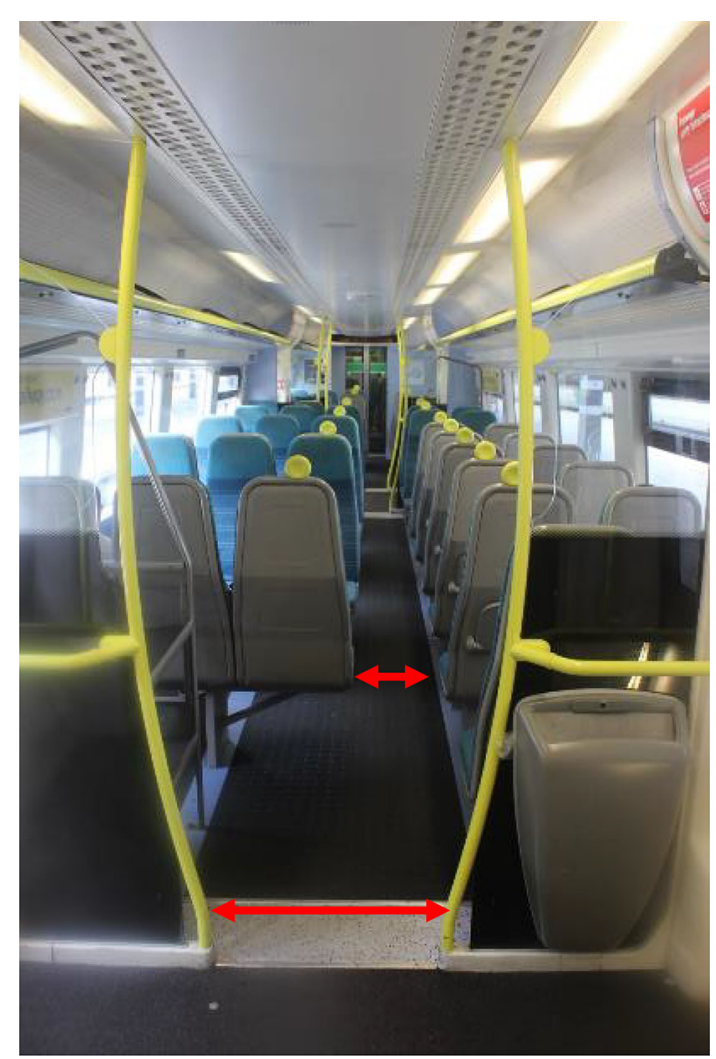

Fig. 2 Aisle widths in British Class 377 vehicle fitted with $3+2$ seating 
we recognise the caveat noted above regarding the relative choice of seats and standing space. The variable is maximised if there are many excess passengers, but the rolling stock has narrow aisles. It is recognised that this concept is perhaps more pertinent to boarding, rather than alighting, since alighters perhaps do not crowd in the vestibules to the same extent as boarders.

\subsection{Infrastructure}

\subsubsection{Distance from Entrance to Exit}

Many researchers have examined the issue of the distance between the door used by the passenger and their point of entry to/exit from the platform. However, previous research has generally concentrated on situations of 'free' (i.e. unreserved) seating. Research in the Zurich area by Bosina et al. $(2015,2017)$ specifically analysed the nonuniform dispersion of passengers along platforms. Their 2015 paper noted that passengers tend to wait around platform furniture, whilst late arrivers remain near the platform entrance, boarding through the nearest doors. It is widely recognised (e.g. Bosina et al. 2017) that passengers arriving at the platform with plenty of time before train departure seek out that part of the train nearest the exit point on their departure platform, thereby minimising the distance to the exit. Oliveira et al. [33] provide some quantified data for the mainline station at Oxford (Britain), with Fox's paper on the same research [21] highlighting deficiencies in the information about train length as a contributor to the uneven loading resulting from a limited number of platform access points. In order to minimise their walking time along the platform, passengers alighting from trains often do so from carriages nearest their preferred exit, but the purpose of inclusion of this variable here is to see if the rates of boarding and alighting through the chosen door are affected by the distance from the entrance/exit.

\subsubsection{Platform Width}

Platform width may impact on boarding and alighting rates if there is insufficient space to accommodate both streams of passengers. It may also reflect on-platform conditions which may force some potential boarders to stand further away than they would like from the optimal door position for boarding. Whilst recognising that measuring platform width is slightly arbitrary (we have generally taken the value at the location of the critical door, even if there is considerable variation in width along the length of a platform), our previous research did demonstrate that platform width was a statistically significant determinant of boarding rates.

\subsubsection{Double-Sided Platforms}

It has long been understood that the provision of separate platforms for boarding and alighting separates different passenger flows, and substantially improves passenger movement rates. Unfortunately, the cost of constructing these prevents their use in only the busiest of locations. However, our data set does include observations at several of these (Sé in Sao Paulo, Stratford in London, and several stations in the core section of the Munich S-Bahn), and our previous research showed this to be a statistically significant determinant of alighting (presumably because an unimpeded platform is available immediately upon disembarkation).

\subsubsection{Platform-Train Gaps and Steps}

The platform-train interface (PTI) is well known to be a major source of risk to railway passengers [34], so understanding how to maximise passenger flow across it is a matter of safety, as well as passenger flow, importance. Heinz [9] provided useful physiological context about the way in which the human brain is able to walk without mental effort, provided that gaps in the surface are typically less than $15 \mathrm{~cm}$. She noted that the impact of height differences $(H)$ on passenger flows in Sweden was best fitted by a function based on $H^{4}$. Observations made by $\mathrm{RCL}$ at British stations with large platform-train gaps [e.g. Bank (Central line); Clapham Junction (platform 15, now substantially improved)] show passengers spending time assessing the gap to be traversed, and what measures they need to take to mitigate any risk and manage their own propulsion: this includes finding grab rails to provide extra 'pull'. Sadly, we have also witnessed people unable to support their own weight plus the extra force generated by the gravity of stepping significantly downwards. Our own programme of work for Crossrail [35] identified a $4 \%$ reduction in passenger flow rates from an increase in the Pythagorean platform-train gap of $10 \mathrm{~cm}$, following Weidmann's [23, Table 4.3] summary of similar impacts across a range of German rolling stock types.

Daamen et al. [7] demonstrated that larger horizontal and vertical gaps both impacted on passenger flow rates, by around $5 \%$ and $10 \%$, respectively.

However, in a matrix of experiments carried out in PAMELA, Fernandez et al. [24] did not always find that passenger movements were maximised with the smallest gaps, and, indeed, it appeared that slight vertical gaps increased movement speeds. This is also in contrast to our previous analysis including data relating to horizontal, vertical and Pythagorean gaps, of which the vertical gap variable was found to be statistically significant-but only for alighting passengers. Two key points need to be made 
from this. First, one needs to be careful in establishing whether the gaps are estimated from vehicle dimensions or recorded during surveys, as loaded trains rest lower on the suspension, reducing (if not eliminating) the $20-\mathrm{mm}$ theoretical gap commonly planned for. Secondly, there has hitherto been no obvious theoretical explanation for this, although we can now proffer some: a small gap may encourage passengers to take a slightly longer stride, thereby effectively leading to an increase in speed compared to a normally shorter one. Alternatively, perhaps people expect a small gap and mentally slow themselves to question if there really is almost no gap. It is clear that greater understanding is needed of this topic.

Seriani et al.'s latest work [36] concentrated on the impacts of horizontal and vertical gaps on groups of passengers with different levels of mobility, highlighting that even quite small gaps can prevent wheelchair users crossing the platform-train gap at all. This implies that the impact of gaps for more able-bodied people might also not be linear.

Height differences in/out of trains may be adjusted for by the use of steps, either within the vestibule, or outside the main car body (perhaps extending as the doors are opened/retracting as doors close). Holloway et al. [37] used the PAMELA laboratory to undertake some structured experiments about the impacts of luggage and steps in/out of the train. Additionally, demonstrating that the impact of luggage increased with an increasing number of steps, the number of steps also had a proportionately greater impact on older passengers.

\subsubsection{Platform Edge/Screen Doors}

Doors or screens to protect the PTI are increasingly popular at the busiest urban stations, to improve safety, reduce litter being blown onto the tracks, etc. Our large sample size should enable the regressions to distinguish their impact separate from that of sheer passenger numbers.

Despite Heinz's physiological explanation suggesting that there should be a negative impact of platform edge (= platform screen) doors on passenger movement rates, Rodriguez et al. [38] claimed to find that, if anything, platform edge doors (PEDs) improved passenger flow rates, However, their analysis seemed to compare a station with no PEDs but a 170-mm gap (Green Park, London) with one with PEDs and a level train entry (Westminster), whilst their monitoring also included gaps in passenger flow of up to $10 \mathrm{~s}$ (a level of variability which could surely dwarf the results). It is also unclear to us how they controlled their results for changes in passenger quantity, and so how they made their deductions about impacts on passenger movement rates.
Somewhat similarly, results from Thoreau et al. [31] were inconsistent with this variable. They noted that passenger movement rates across a wider 200-mm gap seemed to increase with platform screen doors, but (as theory would suggest) rates with a 75-mm gap and PEDs were similar to those in situations with a wider 200-mm gap and no doors, implying a reduction in rates with platform screen doors.

\subsubsection{Inside/Outside}

Although weather is an environmental condition, its effects can be mitigated through investment in infrastructure such as platform canopies (although, to avoid contact with overhead electrification systems, these do not always extend sufficiently to cover the PTI itself). One can conceive of situations in which passenger movement rates are slower for outside, as opposed to inside, conditions. For instance, during icy weather, passengers might step in/out of the train more carefully, whilst if wet, passengers might not wish to stand on the platform and ensure maximum social pressure on boarding rates, instead possibly folding up their umbrellas as they board.

\subsection{Management Actions}

Railway companies would hope that the extent of direct supervision of passenger movement would also impact on pedestrian movement rates, but defining management actions to create an independent variable is not easy. Our previous regression [15] attempted to score management action on a 1-5 scale, which included measures such as levels of staffing, platform markings, physical barriers, etc., but this did not turn out to be a statistically significant variable.

Kuipers et al. [6] provide some examples from the literature of savings in overall passenger movement time from management actions, such as controlling the location of queuing and providing information about departure times (to limit late-running passengers) and train crowding conditions (to encourage passengers to spread out along the train). However, whilst all these measures are certainly important in reducing the variable element of passenger movement time, it is less clear that they affect the rate of movement during clustered boarding or alighting, which is the focus of this analysis.

For the avoidance of doubt, impacts of timetable structure, etc. in trying to minimise the total number of passenger movements per train call are excluded from this analysis. 


\subsection{Summary}

Whilst not exhaustive, the following table provides a summary of some of the more recent single-variable relationships found by previous authors. Data is shown in two forms: absolute values (e.g. Daamen found an average passenger movement rate of 0.91 passenger/s in [7]), and proportionate values (e.g. Harris et al. [15] found that an increase in the number of alighters/door from 10 to 11 increased alighting rates by $8.8 \%$ ) (Table 2).

\section{Analysis}

This section sets out how the data has been collected and analysed. In particular, it sets out how scatter plots, singlevariable analyses, data transformations and correlations have been used to understand which (functional forms of which) variables are likely to contribute most to the statistical performance of the model developed.

\subsection{Data Collection and Programme Selection}

Data collection for all the surveys has been undertaken using a standard procedure originally developed by London Underground, which uses two observers focussed on the critical door of the train. The first observer records the numbers of passengers alighting, boarding (clustered passengers only, i.e. excluding any 'late runners'), remaining in the vestibule and any left behind. The second observer records, to the nearest second, the times of wheel stop, door open, last alighter, first boarder, last clustered boarder, door close initiation, passenger door closure, last door closure (elsewhere on the train) and wheel start. Either before or after the capture of passenger data, data can be acquired for platform and train characteristics, either from direct measurement or engineering drawings. It is important to note that, as almost all surveys comprise over 30 observations, this paper is something of a meta-analysis, since it includes over 6000 data points.

Because we landed up with over 30 variables, the issue of measurement error needs to be considered. Some variables (e.g. those relating to rolling stock dimensions) are associated with data at very high levels of accuracy. Other variables become accurate as a reflection of the method of measurement: for instance, many data elements only refer to the critical door on the train, and therefore no averaging between doors is necessary. Some of the remaining variables may be less accurate (e.g. aisle width net of people's feet might be deemed inaccurate, as people's feet are not identical in length), but the use of a small team of surveyors reduces inter-surveyor discrepancies, whilst the iterative nature of our analytical method means that those without significant variation (hence statistical impact) tend to be dropped from the model, with only impactful variables remaining.

In order to apply different multiple regression models to the data available (or subsets of it), the R statistical package has been used. $\mathrm{R}$ is a system for statistical computation and graphics, providing a programming language, highlevel graphics, interfaces with other languages and debugging facilities.

$\mathrm{R}$ has been used for this analysis for different reasons: first, it has been designed to handle large data sets (larger than Excel, for example) and can still run efficiently while doing so. Secondly, $\mathrm{R}$ is also able to create advanced data visualisations for complex data sets. Thirdly, the $\mathrm{R}$ code generated is reproducible: indeed, the statistical code developed can be applied to any data sets with only a few changes to code and reference data, which made it particularly efficient for disaggregated analyses of parts of the overall data set.

\subsection{Data Transformations}

The aim of the analysis is to find a relationship among the dependent variable (alighting or boarding rate) and the combination of independent variables having an influence on the dependent variable. In order to achieve this aim, independent variables not having a relationship with the dependent variable need to be excluded from the analysis. A full list of the variables available for analysis was shown above in Table 1; we comment here only on variables for which transformation was required.

(Number of) Train Steps ${ }^{1}$ : This variable has been deleted, as the corresponding binary variable appeared to be a better representation of the reality. Indeed, the analysis of the train steps variable is shown in Fig. 3.

There were 165 examples in the data set with zero train steps, and these were, on average, associated with an alighting rate of 1.12 passengers/s. However, the situation of having five steps has only been observed four times and is associated with an average alighting rate of 1.21 passengers/s, apparently implying passengers alight faster when five steps are present than when no steps are present, which is improbable. Even if a situation associated with only four observations is reliable, we cannot judge whether the result is true or not or whether, had we had 165 observations of it, we would not find the same result in terms of alighting rate. Including the variable leads to a counter-intuitive implication that more steps would increase the alighting rate. The insufficiently small sample

\footnotetext{
${ }^{1}$ Note that the graph and the table above represent the relationship between train steps and alighting rate, but a similar situation refers to the relationship between train steps and boarding rate.
} 
Table 2 Summary of results from previous authors

\begin{tabular}{|c|c|c|c|}
\hline Variable & Authors & Location & Rate (passengers/s) or change \\
\hline \multicolumn{4}{|l|}{ Passengers } \\
\hline Number of passengers & Daamen et al. [7] & Slevin laboratory & 0.91 \\
\hline Number of passengers & D'Acierno et al. [14] & Napoli, Italy & 1.16 \\
\hline Number of passengers & Antognoli et al. [17] & Rome, Italy & 0.62 \\
\hline Number of passengers & Holloway et al. [37] & $\begin{array}{l}\text { PAMELA } \\
\text { laboratory }\end{array}$ & 0.38 \\
\hline Number of passengers (boarders and alighters) & Christoforou et al. [20] & Nantes, France & 0.27 \\
\hline Peak passengers & Wiggenraad [10] & Netherlands & 1.04 \\
\hline Off-peak passengers & Wiggenraad [10] & Netherlands & 1.03 \\
\hline No. of mainline passengers (incl. luggage) & Watts et al. [39] & Britain & 0.34 \\
\hline Number of commuters & Weidmann & & 1.45 \\
\hline Number of shoppers & Weidmann & & 1.04 \\
\hline Number of tourists & Weidmann & & 0.99 \\
\hline Number of alighters & $\begin{array}{l}\text { Girnau and Blennemann } \\
\text { [40] }\end{array}$ & Germany & 1.33 \\
\hline Number of alighters & Dirmeier [41] & Germany & 0.90 \\
\hline Number of alighters & Lam et al. $[11]^{*}$ & Hong Kong & 1.06 \\
\hline Number of alighters & Harris et al. [15] & Worldwide & $\begin{array}{l}+8.8 \% \text { per person } \\
\text { if } 10 \text { passengers }\end{array}$ \\
\hline Number of boarders & $\begin{array}{l}\text { Girnau and Blennemann } \\
\text { [40] }\end{array}$ & Germany & 1.23 \\
\hline Number of boarders & Dirmeier [41] & Germany & 1.18 \\
\hline Number of boarders & Lam et al. [11] & Hong Kong & 0.97 \\
\hline Number of boarders & Harris et al. [15] & Worldwide & $+1.8 \%$ per person \\
\hline Ratio of alighters: boarders & Harris et al. [15] & Worldwide & $\begin{array}{l}+1.3 \% \text { alighters, }+0.4 \% \text { boarders, from } 2: 1 \\
\text { to } 3: 1\end{array}$ \\
\hline Passengers with luggage & Weidmann [42] & $\begin{array}{l}\text { Germany/ } \\
\text { Switzerland }\end{array}$ & Up to $200 \%$ slower \\
\hline Passengers with luggage & Daamen et al. [7] & Slevin laboratory & 0.7 passenger/s-25\% (slower) \\
\hline Number of passengers with luggage & Holloway et al. [37] & $\begin{array}{l}\text { PAMELA } \\
\text { laboratory }\end{array}$ & $0.36-5 \%$ \\
\hline Passengers with luggage & Harris and Ehizele [29] & London & -10 to $-83 \%$ (slower) \\
\hline Vehicle load & Palmqvist et al. [25] & Tokyo, Japan & $1 \mathrm{~s} / 10 \%$ increase \\
\hline No. of vestibule passengers & Palmqvist et al. [25] & $\begin{array}{l}\text { Stockholm, } \\
\text { Sweden }\end{array}$ & $0.08 \mathrm{~s} / \mathrm{standee}$ \\
\hline Vestibule occupancy & Harris et al. [15] & Worldwide & $\begin{array}{l}-0.6 \% \text { alighters, }-0.4 \% \text { boarders per } 1 \% \\
\text { increase }\end{array}$ \\
\hline \multicolumn{4}{|l|}{ Rolling stock } \\
\hline Standbacks & Harris et al. [15] & Worldwide & $+2.6 \%$ boarders per $0.1-\mathrm{m}$ increase \\
\hline Standbacks & Seriani and Fujiyama [16] & $\begin{array}{l}\text { PAMELA } \\
\text { laboratory }\end{array}$ & $+3 \%$ boarders per $0.1-\mathrm{m}$ increase \\
\hline Train seating density & Harris et al. [15] & Worldwide & $-16 \%$ per seat $/ \mathrm{m}^{2}$ alighters \\
\hline Inter-door distance & Harris et al. [15] & Worldwide & $-2 \%$ alighters per $\mathrm{m}$ \\
\hline Car area/door width & Harris et al. [15] & Worldwide & $+4 \%$ boarders from 2 to 3 doors/carriage \\
\hline Train type intercity & Wiggenraad [10] & Netherlands & 0.88 \\
\hline Train type local & Wiggenraad [10] & Netherlands & 1.02 \\
\hline Train type double-deck & Wiggenraad [10] & Netherlands & 1.01 \\
\hline \multicolumn{4}{|l|}{ Infrastructure } \\
\hline Number of passengers across one step & Holloway et al. [37] & $\begin{array}{l}\text { PAMELA } \\
\text { laboratory }\end{array}$ & $0.33-12 \%$ \\
\hline
\end{tabular}


Table 2 continued

\begin{tabular}{|c|c|c|c|}
\hline Variable & Authors & Location & Rate (passengers/s) or change \\
\hline Number of passengers across two steps & Holloway et al. [37] & $\begin{array}{l}\text { PAMELA } \\
\text { laboratory }\end{array}$ & $0.30-19 \%$ \\
\hline Pythagorean stepping distance & $\begin{array}{l}\text { Railway Consultancy Ltd } \\
\text { (2004) }\end{array}$ & London & $-4 \%$ per $10-\mathrm{cm}$ increase \\
\hline Vertical stepping distance & Dirmeier [41] & Germany & $\begin{array}{l}-2 \% \text { per } 10-\mathrm{cm} \text { increase }(\mathrm{A}) \\
-13 \% \text { per } 10-\mathrm{cm} \text { increase }(\mathrm{B})\end{array}$ \\
\hline Vertical stepping distance & Weidmann [42] & $\begin{array}{l}\text { Germany/ } \\
\text { Switzerland }\end{array}$ & $-3.9 \%$ per $10 \mathrm{~cm}$ \\
\hline Vertical stepping distance & Harris et al. [15] & Worldwide & $-13 \%$ alighters per $10-\mathrm{cm}$ increase \\
\hline Vertical stepping distance & Seriani and Fujiyama [16] & $\begin{array}{l}\text { PAMELA } \\
\text { laboratory }\end{array}$ & $\begin{array}{l}-6 \% \text { (alighters) } /-10 \% \text { (boarders) per } \\
10 \text {-cm increase }\end{array}$ \\
\hline $\begin{array}{l}\text { Provision of separate platforms for boarders } \\
\text { and alighters }\end{array}$ & Harris et al. [15] & Worldwide & $+43 \%$ alighters \\
\hline \multicolumn{4}{|l|}{ Management } \\
\hline Service type intercity & Wiggenraad [10] & Netherlands & 0.98 \\
\hline Service type local & Wiggenraad [10] & Netherlands & 1.10 \\
\hline
\end{tabular}

*To try to provide direct comparability, Lam's data has been re-stated on the basis of 20 movements/critical door (notionally 10 alighters and 10 boarders) (those estimates taken from our own surveys at the same stations)

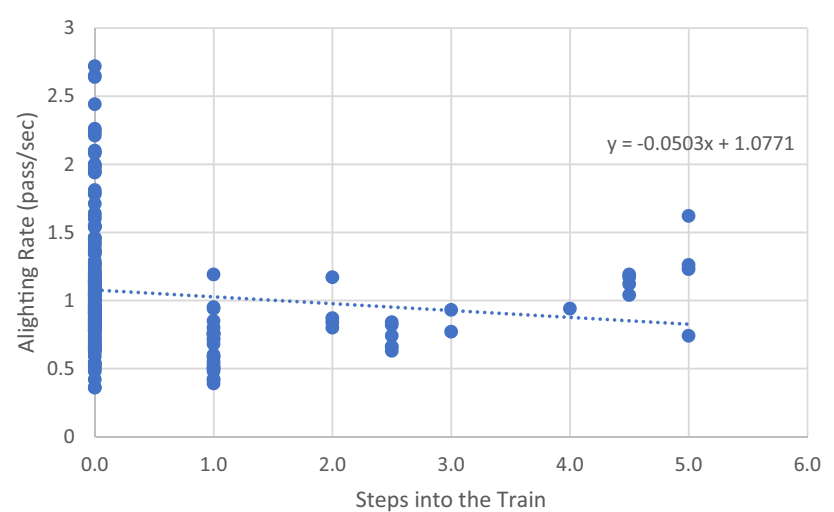

Fig. 3 Relationship between alighting rate and number of steps in the train

of circumstances associated with the higher number of steps therefore led to the decision to only consider zero steps and one or more steps, where enough data are available to compare. Consequently, the 'train steps' variable has been removed, and the corresponding binary variable has been used instead.

Standback width ${ }^{2}$ : The standback width variable seems to be well represented across the sample with no obvious outliers. The standback curve shows that the alighting rate increases up to a standback width of $0.25 \mathrm{~m}$, then it

\footnotetext{
${ }^{2}$ Note that the graph and table above represent the relationship between standback width and alighting rate, but a similar situation refers to the relationship between standback width and boarding rate.
}

decreases until the standback is equal to around $0.6 \mathrm{~m}$ (perhaps as two passengers try to stand in it?), to then increase again, when the standback width is equal to $1 \mathrm{~m}$ or wider (Fig. 4).

This could be explained with the phenomenon of passengers being able to alight the train quickly when a small standback is available (e.g. for minor luggage). However, with a slightly wider standback (say between 0.25 and $0.6 \mathrm{~m}$ wide), passengers wishing to alight at the next station may remain in it, blocking the passage of some alighters. When the standback is really large, however, observations suggest that there is both sufficient room for passengers to remain in the standback whilst alighters (and boarders) can move unimpeded. Consequently, this variable has been replaced with a step function, showing the following values for the following ranges: 1 for standback

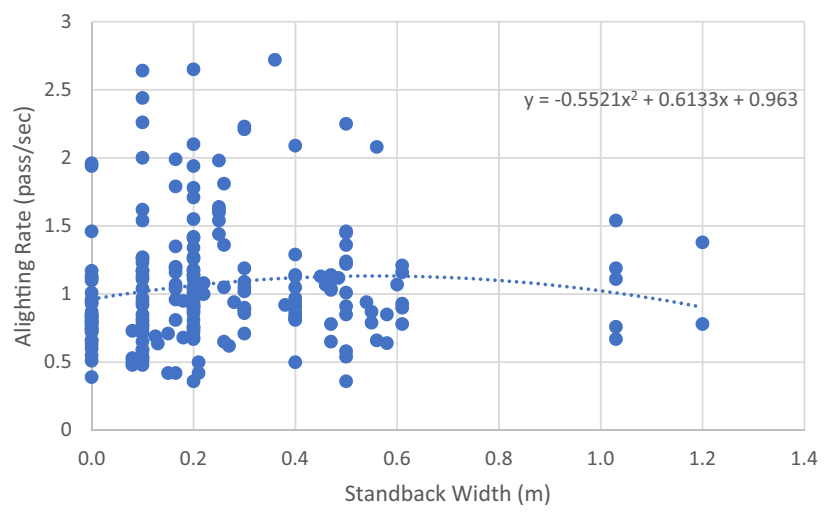

Fig. 4 Relationship between alighting rate and standback width 
width $<0.25 \mathrm{~m}, 2$ for standback width between 0.25 and $0.60 \mathrm{~m}, 3$ for standback width between 0.60 and $1 \mathrm{~m}$, and 4 for standback widths bigger than $1 \mathrm{~m}$ (reflecting multi-user space).

DoorWidth $^{3}$ : For the same reason explained above for the standback width, the door width has been replaced by a door width_step_function (Fig. 5). Whilst the exact thresholds are arguable, we have taken a function showing the following values for the following ranges: 1 for 'DoorWidth' less than $0.90 \mathrm{~m}, 2$ for DoorWidth between 0.90 and $1.30 \mathrm{~m}$, and 3 for DoorWidth bigger than $1.30 \mathrm{~m}$.

Even after these deletions of potential variables, 34 potential explanatory variables remained available for analysis.

\subsection{Scatter Plots and Functions}

Scatter plots have been used to observe relationships between variables and to help understand the hypotheses derived from previous work regarding some of the variables. Separate scatter plots between the dependent and each of the independent variables are shown in the supporting data document, for alighting and boarding separately. For ease of reference, the best single-variable functions are listed in Appendix A, using more complex relationships where appropriate.

In many cases, logical relationship and/or previous research have determined the type of relationship between variables, both in terms of direction (directly/inversely proportional) and sometimes also in terms of shape (e.g. linear or not). A function, chosen among exponential, linear, logarithmic, polynomial (assumption: maximum second order) and power, has been selected to express the relationship between the dependent variable (corresponding to the alighting/boarding rate) and each of the independent variables, keeping in mind not to add complexity to the system, if not needed.

There are a few cases where there is no evident curve fitting the data provided (confirmed by a very low $R^{2}$ for polynomial functions). No function has been associated to them. This reduces the potential number of explanatory variables to 28 .

\subsection{Single-Variable Analysis}

A variable-by-variable analysis produced the results shown in Table 3 for all independent variables, regressed separately and linearly.

\footnotetext{
${ }^{3}$ Note that the graph and table above represent the relationship between door width and alighting rate, but a similar situation refers to the relationship between door width and boarding rate.
}

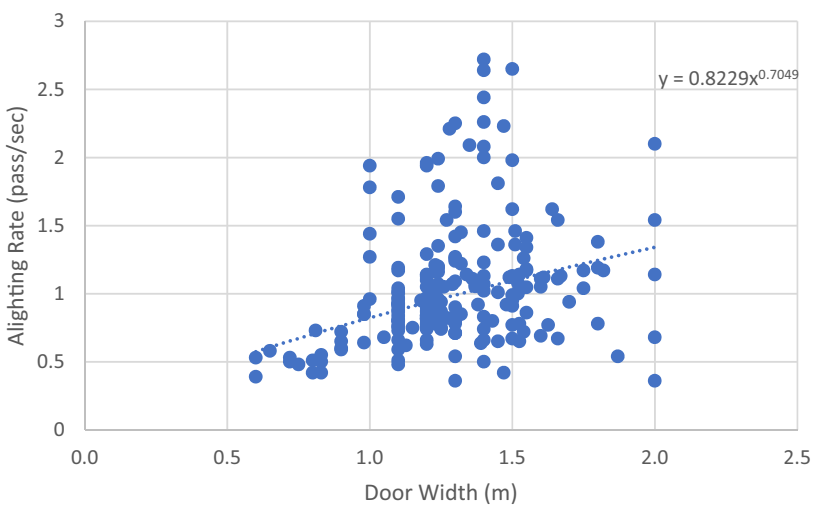

Fig. 5 Relationship between alighting rate and door width

\subsection{Correlations}

Correlation matrices have been developed to show the relationship between the 28 independent variables selected above, differentiated by alighters and boarders. The matrices identify the independent variables strictly correlated to each other, which may need to be excluded from the next steps of the analysis to avoid multicollinearity issues.

Results obtained (in absolute value, as the sign only indicates if the relationship is directly or inversely proportional) are shown in Tables 4 and 5 . The variables that are strictly correlated to each other are in red, the variables that are less correlated to each other are in yellow and the variables that are almost not correlated to each other are in green.

Unlike some statistical analyses, however, it is appropriate to include within the data set for analysis variables which are closely correlated but nevertheless are independent. For instance, door width and aisle width are rolling stock variables which can be designed to be independent, even if metro trains normally have larger values of both than long-distance rolling stock. Similarly, inter-door distance is correlated with the 'outside protected dummy', because these are conditions which generally prevail more on mainline railways, but they can nevertheless be addressed separately.

However, among the 28 variables taken into consideration, some are clearly alternative formulations of the same measure (e.g. 3a, 3b, 3c), where it would be inappropriate to include all formulations. Among the alternative formulations of the same measure, the formulations strongly correlated (correlation $>0.5$ ) to fewer other variables have been selected for one of the following regression models, leaving 18 separate and uncorrelated variables. However, other models including all variables have been developed as well, and results have been compared. 
Table 3 Single-variable results for passenger movement rates (passengers/s)

\begin{tabular}{|c|c|c|c|c|c|c|}
\hline \multirow[t]{2}{*}{ Variable } & \multicolumn{3}{|l|}{ Alighting } & \multicolumn{3}{|l|}{ Boarding } \\
\hline & Coefficient & Adjusted $R^{2}$ & $t$-Statistic & Coefficient & Adjusted $R^{2}$ & $t$-Statistic \\
\hline \multicolumn{7}{|l|}{ Passenger variables } \\
\hline Number of passengers & 0.029 & 0.39 & 11.49 & 0.027 & 0.35 & 10.94 \\
\hline Boarding: alighting ratio & 0.017 & 0.028 & 2.66 & 0.003 & 0.0001 & 0.99 \\
\hline Boarders $\times$ alighters product & 0.001 & 0.23 & 7.94 & 0.0009 & 0.22 & 7.87 \\
\hline Vestibule load (passengers) & -0.005 & 0.00007 & -1.01 & 0.004 & 0.0007 & 1.07 \\
\hline Vestibule capacity (passengers) & -0.18 & 0.0001 & -1.01 & 0.12 & -0.001 & 0.88 \\
\hline Alighters/boarders in excess of vestibule capacity & 0.019 & 0.22 & 7.82 & 0.015 & 0.20 & 7.41 \\
\hline$\%$ of passengers with large luggage & -0.025 & 0.03 & -2.64 & -0.02 & 0.08 & -4.46 \\
\hline \multicolumn{7}{|l|}{ Infrastructure variables } \\
\hline Outside unprotected D & -0.40 & 0.095 & -4.80 & -0.38 & 0.14 & -6.10 \\
\hline Double-sided platform D & 0.19 & 0.0003 & 1.04 & 0.004 & -0.005 & 0.04 \\
\hline Platform edge doors D & 0.31 & 0.04 & 3.12 & 0.31 & 0.065 & 4.04 \\
\hline Platform width (m) & 0.11 & 0.05 & 3.40 & 0.098 & 0.06 & 3.89 \\
\hline Egress distance $(\mathrm{m})$ & -0.002 & 0.008 & -1.65 & -0.002 & 0.02 & -2.23 \\
\hline Vertical step distance (mm) & -0.002 & 0.095 & -4.79 & -0.002 & 0.18 & -7.02 \\
\hline Horizontal step distance (mm) & -0.0005 & -0.001 & -0.83 & -0.001 & 0.032 & -2.87 \\
\hline Pythagorean step distance (mm) & -0.002 & 0.11 & -5.12 & -0.002 & 0.24 & -8.45 \\
\hline Management quality index D & 0.11 & 0.06 & 3.68 & 0.08 & 0.05 & 3.38 \\
\hline \multicolumn{7}{|l|}{ Rolling stock variables } \\
\hline Double-deck stock D & 0.04 & -0.005 & 0.22 & -0.04 & -0.004 & -0.30 \\
\hline Train steps & -0.05 & 0.01 & -1.76 & -0.09 & 0.07 & -4.24 \\
\hline Train steps D & -0.32 & 0.08 & -4.43 & -0.43 & 0.25 & -8.44 \\
\hline Doors/car & 0.23 & 0.23 & 7.99 & 0.13 & 0.14 & 5.97 \\
\hline Inter-door distance (m) & -0.04 & 0.13 & -5.57 & -0.04 & 0.21 & -7.75 \\
\hline Door width (m) & 0.49 & 0.07 & 4.20 & 0.54 & 0.14 & 6.15 \\
\hline Standback width (m) & 0.26 & 0.11 & 5.19 & 0.51 & 0.09 & 4.84 \\
\hline Grab poles D & 0.06 & -0.004 & 0.29 & -0.08 & -0.003 & -0.54 \\
\hline Vestibule size $\left(\mathrm{m}^{2}\right)$ & 0.10 & 0.06 & 3.82 & 0.14 & 0.19 & 7.17 \\
\hline Vestibule capacity (passengers) & 0.02 & 0.14 & 5.80 & 0.02 & 0.25 & 8.64 \\
\hline Aisle width at vestibule (m) & 0.36 & 0.12 & 5.52 & 0.34 & 0.18 & 6.91 \\
\hline Aisle width net of feet (m) & 0.51 & 0.19 & 7.16 & 0.47 & 0.26 & 8.78 \\
\hline Saloon exit difficulty (index) & 0.009 & 0.05 & 3.59 & 0.005 & 0.03 & 2.65 \\
\hline Car area $\left(\mathrm{m}^{2}\right)$ & 0.002 & 0.002 & 1.16 & -0.002 & 0.003 & -1.30 \\
\hline Car area/door width $(\mathrm{m})$ & -0.02 & 0.13 & -5.76 & -0.018 & 0.28 & -9.34 \\
\hline Seats/car & -0.004 & 0.04 & -3.25 & -0.005 & 0.12 & -5.55 \\
\hline$\%$ of seats longitudinal & 0.005 & 0.16 & 6.41 & 0.004 & 0.22 & 7.91 \\
\hline Seats/train width $(/ \mathrm{m})$ & -0.14 & 0.14 & -6.00 & -0.15 & 0.23 & -8.21 \\
\hline Seating density $\left(/ \mathrm{m}^{2}\right)$ & -0.73 & 0.16 & -6.41 & -0.61 & 0.17 & -6.90 \\
\hline
\end{tabular}

Source: separate spreadsheet analysis. Variables marked as D are dummy variables. Degrees of freedom $=224$

$t$-statistics $> \pm 2.63$ are significant at the $99 \%$ level, and those $> \pm 3.39$ at the $99.9 \%$ level

Vestibule capacity varies between 4 and 7 passengers $/ \mathrm{m}^{2}$, depending upon journey length and local planning standards

Saloon exit difficulty is the ratio of the number of passengers attempting to make the movement divided by the aisle width (net of seated passengers' feet) 
Table 4 Correlation matrix for variables affecting alighting rate

\begin{tabular}{|c|c|c|c|c|c|c|c|c|c|c|c|c|c|c|c|c|c|c|c|c|c|c|c|c|c|c|c|c|}
\hline & & & & Vestibule & Alighters_i & & & & Ave & Vertical & Horiz & Pythagore & e Managem & 4 Train & & InterDoor & or DoorWidt & t Standback & & vest & Aisle & Aislewidt & Saloon & Cararea & & \%ofseats & s seats/ & Seating \\
\hline & Numberoff & & Vestibule & LoadVs & $n_{-X s_{-} \text {of_v }}$ & swith & Outside & Plattorm & Egress & Step & Step & anstep & entaualit & Steps_ & Doorsperc & c Distance_ & h_step & Width_step & Vestibule & Capacity_ & Widthat & hNetof & Exit & vsDoor & SeatsperC L & Longi. & Train & Density_ \\
\hline & lighters & A_X_B & Load_pass & Capacity & est_cap & Luggage & Dummy & Witth_m & Dist_m & Dist_mm & Dist_mm D & Dist_mm & yindex & binary & ar & $\mathrm{m}$ & ffunction & function & Size_m2 & pass $\quad \checkmark$ & vestibule & Feet_m & Difficulty $v$ & Width_m ar & & tudinal & width & seats $/ \mathrm{m} 2$ \\
\hline lumberofAlighters & 1.00 & 0.74 & 0.01 & 0.02 & 0.86 & -0.12 & -0.07 & 0.19 & -0.05 & -0.06 & -0.10 & -0.15 & 0.32 & -0.09 & 0.20 & -0.0 & 0.21 & 0.03 & 0.17 & 0.23 & 0.28 & 0.31 & 0.69 & -0.09 & -0.01 & 0.25 & -0.22 & -0.18 \\
\hline$x \_B$ & 0.74 & 1.00 & 0.08 & 0.09 & 0.67 & -0.13 & -0.13 & 0.12 & -0.01 & -0.14 & -0.12 & -0.23 & 0.32 & -0.10 & 0.21 & .0 .0 & 0.24 & 0.06 & 0.19 & 0.26 & 0.31 & 0.37 & 0.47 & -0.10 & 0.00 & 0.28 & -0.23 & -0.21 \\
\hline /estibuleLoad_pass & 0.01 & 0.08 & 1.00 & 0.92 & 0.52 & -0.09 & -0.26 & 0.24 & -0.19 & -0.25 & -0.18 & -0.29 & 0.28 & -0.17 & 0.37 & -0.2 & 0.24 & 0.13 & 0.29 & 0.47 & 0.28 & 0.23 & 0.40 & -0.31 & -0.21 & 0.34 & -0.35 & -0.29 \\
\hline |estibuleloadVs Capacity & 0.02 & 0.09 & 0.92 & 1.00 & 0.50 & -0.12 & -0.27 & 0.19 & -0.19 & -0.23 & .0 .19 & -0.27 & 0.23 & -0.17 & 0.34 & -0.2 & 0.21 & 0.01 & 0.13 & 0.27 & 0.19 & 0.18 & 0.43 & -0.31 & -0.23 & 0.31 & -0.30 & -0.25 \\
\hline Aighters_x__of_remain_vest_cap & 0.86 & 0.67 & 0.52 & 0.50 & 1.00 & -0.14 & -0.17 & 0.27 & -0.13 & -0.16 & -0.17 & -0.26 & 0.40 & -0.14 & 0.33 & -0.1 & 0.27 & 0.06 & 0.24 & 0.38 & 0.35 & 0.35 & 0.81 & -0.21 & -0.10 & 0.36 & -0.34 & -0.28 \\
\hline ercentageWithlugagage & -0.12 & -0.13 & -0.09 & -0.12 & -0.14 & 1.00 & 0.05 & -0.06 & -0.01 & 0.18 & -0.03 & 0.14 & 0.00 & 0.20 & -0.15 & 0.0 & -0.28 & -0.10 & -0.23 & -0.25 & -0.10 & -0.21 & -0.07 & 0.22 & -0.01 & -0.10 & 0.08 & 0.05 \\
\hline Outside UnprotectedDummy & -0.07 & -0.13 & -0.26 & -0.27 & -0.17 & 0.05 & 1.00 & -0.10 & 0.19 & 0.43 & 0.22 & 0.48 & -0.20 & 0.27 & .0 .52 & 0.6 & -0.35 & -0.15 & -0.32 & -0.39 & -0.29 & .0 .39 & 0.02 & 0.53 & 0.42 & -0.45 & 0.43 & 0.46 \\
\hline PlatformWidth_m & 0.19 & 0.12 & 0.24 & 0.19 & 0.27 & -0.06 & -0.10 & 1.00 & -0.17 & -0.29 & 0.02 & -0.25 & 0.12 & -0.11 & 0.25 & -0.0 & 0.11 & 0.08 & 0.16 & 0.27 & 0.30 & 0.26 & 0.10 & -0.13 & .0 .09 & 0.24 & -0.29 & -0.23 \\
\hline AveEgress Dist_m & -0.05 & -0.01 & -0.19 & -0.19 & -0.13 & -0.01 & 0.19 & -0.17 & 1.00 & 0.21 & 0.22 & 0.30 & -0.15 & 0.04 & .0 .22 & 0.2 & -0.23 & -0.02 & -0.10 & -0.18 & -0.15 & -0.19 & -0.11 & 0.20 & 0.15 & .0 .32 & 0.33 & 0.20 \\
\hline VerticalstepDist_mm & -0.06 & -0.14 & -0.25 & -0.23 & -0.16 & 0.18 & 0.43 & .0 .29 & 0.21 & 1.00 & -0.03 & 0.85 & -0.12 & 0.28 & .0 .46 & 0.4 & -0.36 & -0.09 & -0.31 & -0.39 & -0.41 & .0 .40 & 0.01 & 0.49 & 0.26 & -0.38 & 0.37 & 0.36 \\
\hline IorizstepDist_mm & -0.10 & -0.12 & -0.18 & .0 .19 & -0.17 & -0.03 & 0.22 & 0.02 & 0.22 & -0.03 & 1.00 & 0.44 & -0.13 & 0.15 & -0.22 & 0.36 & -0.22 & -0.06 & -0.14 & -0.18 & -0.11 & .0 .21 & -0.10 & 0.29 & 0.29 & -0.35 & 0.30 & 0.20 \\
\hline ythagoreanstep Dist_mm & -0.15 & -0.23 & .0 .29 & .0 .27 & -0.26 & 0.14 & 0.48 & .0 .25 & 0.30 & 0.85 & 0.44 & 1.00 & -0.17 & 0.35 & .0 .51 & 0.5 & -0.45 & -0.12 & -0.36 & -0.45 & -0.45 & .0 .45 & .0 .08 & 0.59 & 0.40 & .0 .51 & 0.49 & 0.45 \\
\hline Managementaualityindex & 0.32 & 0.32 & 0.28 & 0.23 & 0.40 & 0.00 & -0.20 & 0.12 & -0.15 & -0.12 & -0.13 & -0.17 & 1.00 & -0.16 & 0.40 & -0.2 & 0.22 & 0.15 & 0.31 & 0.41 & 0.37 & 0.29 & 0.29 & -0.25 & .0 .08 & 0.42 & -0.36 & -0.18 \\
\hline Trainsteps_binary & -0.09 & -0.10 & -0.17 & -0.17 & -0.14 & 0.20 & 0.27 & -0.11 & 0.04 & 0.28 & 0.15 & 0.35 & -0.16 & 1.00 & .0.39 & 0.4 & -0.34 & -0.21 & -0.27 & -0.32 & -0.47 & .0 .36 & 0.06 & 0.68 & 0.68 & .0 .43 & 0.45 & 0.45 \\
\hline Doorspercar & 0.20 & 0.21 & 0.37 & 0.34 & 0.33 & -0.15 & .0 .52 & 0.25 & -0.22 & .0 .46 & -0.22 & .0 .51 & 0.40 & .0 .39 & 1.00 & .0 .7 & 0.37 & 0.08 & 0.30 & 0.55 & 0.46 & 0.60 & 0.01 & -0.70 & .0 .45 & 0.73 & -0.68 & .0 .60 \\
\hline Interdoordistance_m & -0.03 & -0.05 & -0.28 & -0.27 & -0.14 & 0.04 & 0.66 & -0.08 & 0.21 & 0.49 & 0.30 & 0.59 & -0.23 & 0.47 & .0.74 & $1.0 \mathrm{r}$ & -0.40 & -0.22 & -0.36 & -0.46 & -0.46 & -0.43 & 0.07 & 0.84 & 0.66 & -0.63 & 0.60 & 0.58 \\
\hline Doorwidth_step.function & 0.21 & 0.24 & 0.24 & 0.21 & 0.27 & -0.28 & -0.35 & 0.11 & -0.23 & -0.36 & .0 .22 & -0.45 & 0.22 & -0.34 & 0.37 & .0 .4 & 1.00 & 0.15 & 0.68 & 0.63 & 0.43 & 0.45 & 0.13 & -0.54 & -0.31 & 0.56 & -0.49 & -0.52 \\
\hline StandbackWidth_step.function & 0.03 & 0.06 & 0.13 & 0.01 & 0.06 & -0.10 & -0.15 & 0.08 & -0.02 & -0.09 & -0.06 & -0.12 & 0.15 & -0.21 & 0.08 & -0.2 & 0.15 & 1.00 & 0.61 & 0.50 & 0.28 & 0.04 & 0.08 & -0.23 & -0.22 & 0.17 & -0.14 & -0.18 \\
\hline Vestibulesize_m2 & 0.17 & 0.19 & 0.29 & 0.13 & 0.24 & -0.23 & -0.32 & 0.16 & -0.10 & -0.31 & -0.14 & .0 .36 & 0.31 & -0.27 & 0.30 & -0.3 & 0.68 & 0.61 & 1.00 & 0.89 & 0.43 & 0.41 & 0.13 & -0.42 & -0.21 & 0.43 & -0.35 & -0.44 \\
\hline vestibulecapacity_pass & 0.23 & 0.26 & 0.47 & 0.27 & 0.38 & -0.25 & -0.39 & 0.27 & -0.18 & -0.39 & -0.18 & .0 .45 & 0.41 & -0.32 & 0.55 & -0.4 & 0.63 & 0.50 & 0.89 & 1.00 & 0.57 & 0.56 & 0.16 & -0.51 & .0 .28 & 0.58 & -0.51 & .0 .53 \\
\hline AisteWidthatvestibule & 0.28 & 0.31 & 0.28 & 0.19 & 0.35 & -0.10 & -0.29 & 0.30 & -0.15 & -0.41 & -0.11 & .0 .45 & 0.37 & -0.47 & 0.46 & -0.4 & 0.43 & 0.28 & 0.43 & 0.57 & 1.00 & 0.55 & 0.05 & -0.52 & -0.47 & 0.65 & -0.63 & -0.56 \\
\hline AislewidthNetofPeoplefeet_m & 0.31 & 0.37 & 0.23 & 0.18 & 0.35 & -0.21 & -0.39 & 0.26 & -0.19 & -0.40 & -0.21 & -0.45 & 0.29 & .0 .36 & 0.60 & -0.4 & 0.45 & 0.04 & 0.41 & 0.56 & 0.55 & 1.00 & .0 .09 & .0.49 & .0.35 & 0.68 & -0.71 & .0 .52 \\
\hline SaloonExititifificulty & 0.69 & 0.47 & 0.40 & 0.43 & 0.81 & -0.07 & 0.02 & 0.10 & -0.11 & 0.01 & -0.10 & -0.08 & 0.29 & 0.06 & 0.01 & 0.0 & 0.13 & 0.08 & 0.13 & 0.16 & 0.05 & .0 .09 & 1.00 & 0.03 & 0.10 & 0.03 & 0.01 & 0.00 \\
\hline CarareavsDoorwidth_m & -0.09 & -0.10 & -0.31 & -0.31 & -0.21 & 0.22 & 0.53 & -0.13 & 0.20 & 0.49 & 0.29 & 0.59 & -0.25 & 0.68 & -0.70 & 0.8 & -0.54 & -0.23 & -0.42 & -0.51 & -0.52 & .0 .49 & 0.03 & 1.00 & 0.77 & -0.67 & 0.65 & 0.56 \\
\hline Seatspercar & -0.01 & 0.00 & .0 .21 & .0 .23 & -0.10 & -0.01 & 0.42 & -0.09 & 0.15 & 0.26 & 0.29 & 0.40 & -0.08 & 0.68 & .0 .45 & 0.6 & -0.31 & -0.22 & -0.21 & -0.28 & -0.47 & .0 .35 & 0.10 & 0.77 & 1.00 & -0.56 & 0.61 & 0.71 \\
\hline Percentageofiseatslong itudinal & 0.25 & 0.28 & 0.34 & 0.31 & 0.36 & -0.10 & -0.45 & 0.24 & -0.32 & -0.38 & -0.35 & -0.51 & 0.42 & -0.43 & 0.73 & .0 .6 & 0.56 & 0.17 & 0.43 & 0.58 & 0.65 & 0.68 & 0.03 & -0.67 & .0 .56 & 1.00 & -0.86 & -0.66 \\
\hline loofseatsPertrainWidth & -0.22 & -0.23 & -0.35 & .0 .30 & -0.34 & 0.08 & 0.43 & .0 .29 & 0.33 & 0.37 & 0.30 & 0.49 & -0.36 & 0.45 & -0.68 & 0.6 & -0.49 & -0.14 & -0.35 & -0.51 & -0.63 & 0.071 & 0.01 & 0.65 & 0.61 & .0 .86 & 1.00 & 0.67 \\
\hline atingDensity_seats_per_m2 & -0.18 & .0 .21 & -0.29 & -0.25 & -0.28 & 0.05 & 0.46 & -0.23 & 0.20 & 0.36 & 0.20 & 0.45 & -0.18 & 0.45 & .0 .60 & 0.5 & -0.52 & .0 .18 & -0.44 & .0 .53 & -0.56 & .0 .52 & 0.00 & 0.56 & 0.71 & .0 .66 & 0.67 & 1.00 \\
\hline
\end{tabular}

\subsection{Stepwise Regressions}

The method used for the selection of the independent variables to include in the analysis was stepwise regression, which is a systematic search algorithm to find the best model. The stepwise regression performs the searching process automatically and selects the best combination of independent variables that describe the dependent variable. The selection of the best variables follows the Akaike information criterion (AIC), and the direction of the regression is both forward and backward selection. It means that, starting with no predictors, the most contributive predictors are sequentially added (like forward selection). After adding each new variable, any variables that no longer provide an improvement in the model fit are removed (like backward selection). This iterative approach considered the statistical significance of all variables at each stage after recalculation; only variables with $p$-values $<0.1573$ (the default in the software used) were then omitted, whether these had been significant in previous iterations or not. The summary of the stepwise regression shows the selected best variables and related parameters. An alternative approach would be to consider the variables which are most easily addressed practically, an issue to which we return in Table 9.

Different stepwise regression models have been developed, all of them including a non-null intercept. Indeed, since very low numbers of passengers have already been taken into account (by excluding all values less than 1 from the original database), the models will include an intercept. Note that the models below, including an intercept, are only relevant when there is at least one passenger movement per door. The different models developed are as follows:

- Multiple regression 1: multiple linear stepwise regression between the dependent variable and the 34 original independent variables, with a non-null intercept. Each of the variables introduced in the model is assumed to be linearly related to the dependent variable. Results of the statistically significant variables are shown in Appendix A.

- Multiple regression 2: multiple linear stepwise regression between the dependent variable and the 18 selected independent variables (selection based on the correlation matrix), with a non-null intercept. Each of the variables introduced in the model is assumed to be linearly related to the dependent variable.

- Multiple regression 3: multiple polynomial stepwise regression between the dependent variable and the 18 selected independent variables (selection based on the correlation matrix), with a non-null intercept. Each of the variables introduced in the model is assumed to be represented by a function, corresponding to the function expressing the relationship between the dependent variable and each independent variable (see 'Scatter Plots and Functions').

- Multiple regression 4: multiple polynomial stepwise regression between the dependent variable and the 28 selected independent variables (selection based on the scatter plots), with a non-null intercept. Each of the variables introduced in the model is assumed to be represented by a function, corresponding to the function expressing the relationship between the dependent variable and each independent variable (see 'Scatter Plots and Functions'). 


\section{Results}

\subsection{Main Regressions}

\section{Alighters:}

Multiple Regression 1

Ca11:

$1 \mathrm{~m}$ (formula = A7ightingRate_pass_sec $\sim$ NumberofA1ighters + A7ighters_in_xs_of_remaining_vest_cap + DoubleSidedTrainDummy + verticalstepDist_mm + PythagoreanStepDist_mm +

InterDoorDistance_m + Doorwidth_step_function + Standbackwidth_step_function +

vestibulesize_m2 + vestibulecapacity_pass + SaloonExitDifficulty,

data = DB3ANoNA, na. action = na.exclude)

Residuals:

Min 10 Median $30 \quad$ Max

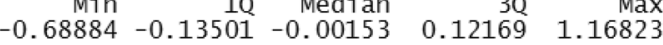

Coefficients :

\begin{tabular}{|c|c|c|c|c|c|}
\hline & & & & & \\
\hline (Intercept) & 0.6738300 & 0.1504303 & 4.479 & $1.42 \mathrm{e}-05$ & k*k \\
\hline NumberofAlịghters & 0.0529082 & 0.0040742 & 12.986 & $<2 \mathrm{e}-16$ & $* k *$ \\
\hline A7ighters_in_xs_of_remaining_vest_cap & -0.0180697 & 0.0051251 & -3.526 & 0.0005 & $* * *$ \\
\hline ublesidedTrainDummy & 0.5 & & 4. & $9.77 \epsilon$ & *** \\
\hline ertica1stepDist_mm & -0.0 & & & & $* *$ \\
\hline ist_mm & & & 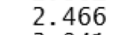 & 717 & $*$ \\
\hline & -0. & & -3.9 & & $* * *$ \\
\hline tion & 0.1 & & 3.000 & & ** \\
\hline StandbackWijth_ste & 0.0 & & & & \\
\hline vestibulesize_m2 & -0.166 & & & & ** \\
\hline bu7ecapacity_pass & 0.018 & & & & ** \\
\hline SaloonExitDifficulty & -0.0064997 & 0.00 & -2.230 & 0.027142 & \\
\hline
\end{tabular}

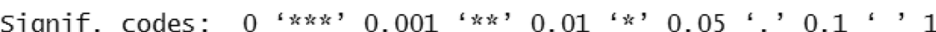

Residual standard error: 0.2592 on 159 degrees of freedom

Mu7tiple R-squared: 0.6924 , Adjusted R-squared: 0.6711

F-statistic: 32.53 on 11 and 159 DF, p-value: $<2.2 \mathrm{e}-16$

Mu7tiple Regression 2

Ca11:

$1 \mathrm{~m}$ (formula $=$ AlightingRate_pass_sec $\sim$ NumberofAlighters + VestibuleLoadvscapacity + PercentagewithLuggage + outsideunprotectedDummy + Platformwidth_m + HorizStepDist_mm + DoorsPerCar + InterDoorDistance_m, data $=$ DB3A, na. action = na.exclude)

Residuals:

Min $10 \quad$ Median $30 \quad \operatorname{Max}$

$\begin{array}{lllll}-0.79299 & -0.17385 & -0.01731 & 0.12901 & 1.16455\end{array}$

Coefficients:

\begin{tabular}{|c|c|c|c|c|c|}
\hline & Estimate & std. Error & t valu & $\operatorname{Pr}(>t$ & \\
\hline (Intercept) & 0.6302119 & 0.1578188 & 3.993 & $9.15 e-05$ & $* * *$ \\
\hline NumberofAlighters & 0.0252974 & 0.0021809 & 11.599 & $<2 \mathrm{e}-16$ & k*k \\
\hline VestibuleLoadvscapacity & -0.6645940 & 0.1229207 & -5.407 & $1.82 \mathrm{e}-07$ & $* * *$ \\
\hline PercentagewithLuggage & -0.0120642 & 0.0062749 & -1.923 & 0.055950 & . \\
\hline OutsideunprotectedDummy & -0.1132247 & 0755355 & -1.499 & 5461 & \\
\hline Platformwidth_m & 0.0407892 & 861 & 782 & 223 & . \\
\hline HorizStepDist_mm & 0.0005903 & 0004031 & 1.464 & 0.144706 & \\
\hline DoorsPerCar & 0.1157983 & 0343699 & 3.369 & 0.000905 & $* * *$ \\
\hline InterDoorDistance_m & -0.0191556 & 0.0076891 & -2.4 & 0.01 & * \\
\hline
\end{tabular}

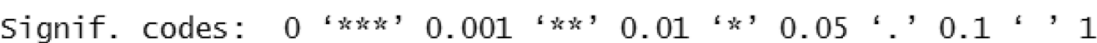

Residual standard error: 0.2889 on 200 degrees of freedom

(1 observation deleted due to missingness)

Multiple R-squared: 0.6072 , Adjusted R-squared: 0.5915

F-statistic: 38.64 on 8 and 200 DF, p-value: $<2.2 \mathrm{e}-16$ 
Mu7tiple Regression 3

Ca11:

$1 \mathrm{~m}$ (formula = AlightingRate_pass_sec $\sim$ NumberofAlighters_F + A_X_B_F + VestibuleLoadvscapacity_F + PercentagewithLuggage_F + Platformwidth_m_F + DoorsPerCar_F + InterDoorDistance_m_F + SaloonExitDifficulty_F, data $=$ DB 3A, na.action = na. exclude)

Residuals:
Min
10 Median

$-0.73471-0.15749-0.01313$

0.14046

$\operatorname{Max}$

Coefficients:

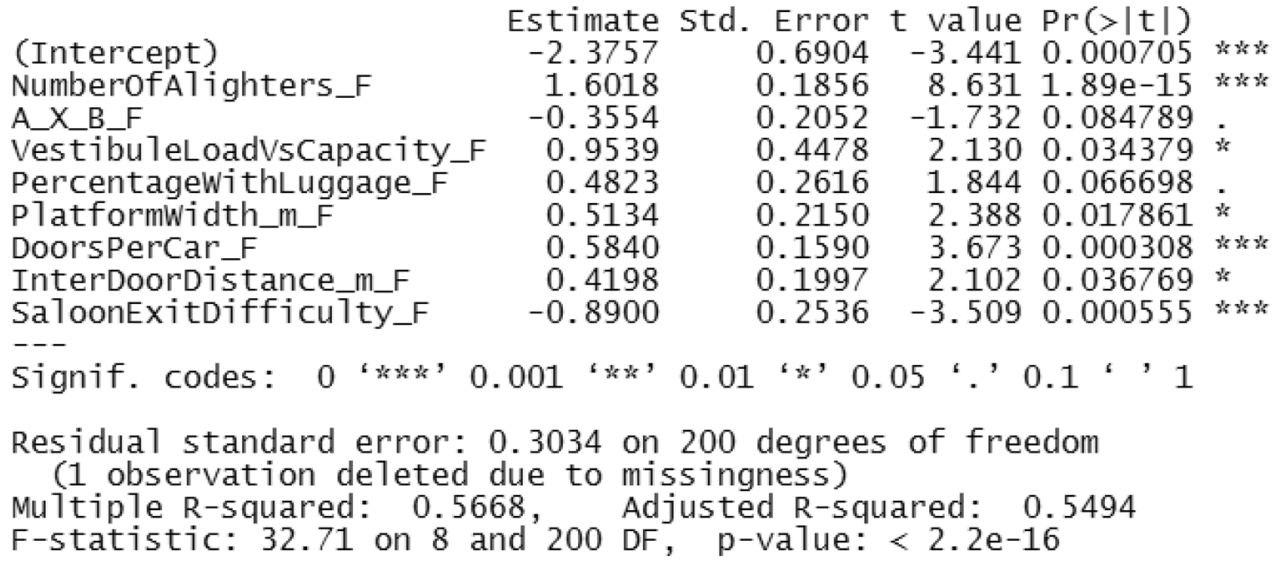

Mu1tiple Regression 4

Ca11:

$1 \mathrm{~m}$ (formula $=$ AlightingRate_pass_sec $\sim$ NumberofA1ighters_F + A_X_B_F + VestibuleLoad_pass_F + PlatformWidth_m_F + Vertica1stepDist_mm_F + Trainsteps_binary_F + DoorsPerCar_F + Standbackwidth_step_function_F + vestibulesize_m2_F + vestibulecapacity_pass_F + AislewidthNetofPeopleFeet_m_F + SaloonExitDifficulty_F, data = DB3A, na.action = na.exclude)

Residua7s:

$\begin{array}{rrrrr}\text { Min } & 1 Q & \text { Median } & 3 Q & \text { Max } \\ -0.75548 & -0.15220 & -0.01311 & 0.11804 & 1.29992\end{array}$

Coefficients:

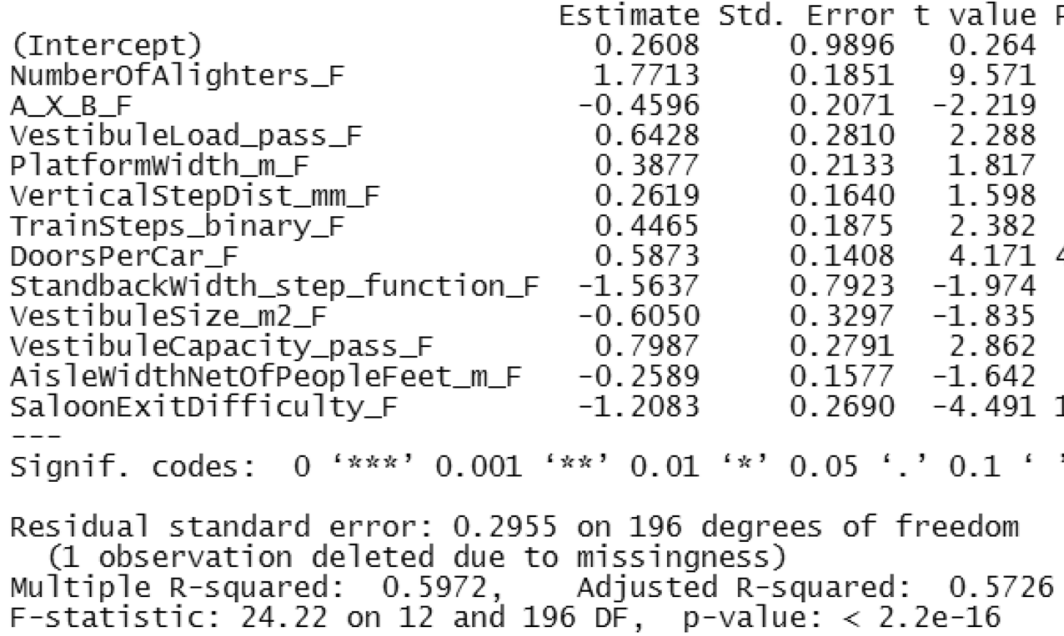


Boarders:

Multiple Regression 1
Ca11:
1m(formula = BoardingRate_pass_sec $\sim$ NumberofBoarders + B_A_Ratio +
VestibuleLoad_pass + Boarders_in_xs_of_remaining_vest_cap +
PercentagewithLuggage + PlatformWidth_m + Trainsteps_binary +
DoorsPerCar + InterDoorDistance_m + StandbackWidth_step_function +
GrabPolesDumm + CarAreavsDoorwidth_m + A_X_B, data = DB3BNoNA,
na.action = na.exclude)

Residuals:

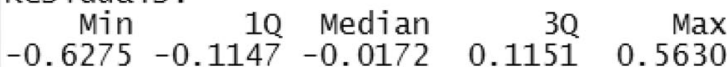

Coefficients:

(Intercept)

NumberofBoarders

B_A_Ratio

VestibuleLoad_pass

Boarders_in_xs_of_remaining_vest_cap

PercentagewithLuggage

Platformwidth_m

Trainsteps_binary

DoorsPercar

InterDoorDistance m

Standbackwidth_step_function

GrabPolesDummy

CarAreavsDoorwidth_m

A_X_B

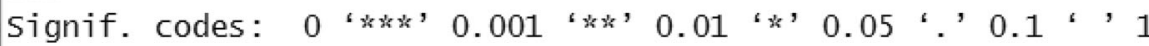

Residual standard error: 0.1888 on 163 degrees of freedom

Multiple R-squared: 0.7013 , Adjusted R-squared: 0.6775

F-statistic: 29.44 on 13 and $163 \mathrm{DF}$, p-value: $<2.2 \mathrm{e}-16$
Estimate std. Error $\mathrm{t}$ value $\operatorname{Pr}(>|\mathrm{t}|)$

$0.8516537 \quad 0.1179401 \quad 7.221 \quad 1.87 \mathrm{e}-11$ k*

$\begin{array}{lllll}0.0891882 & 0.0274804 & 3.246 & 0.001423 & * *\end{array}$

$\begin{array}{llll}0.0030757 & 0.0021039 & 1.462 & 0.145684\end{array}$

$\begin{array}{llllll}0.0597971 & 0.0267404 & 2.236 & 0.026695 & *\end{array}$

$\begin{array}{lllll}-0.0735236 & 0.0276480 & -2.659 & 0.008612 & * * \\ -0.0074781 & 0.0028339 & -2.639 & 0.009127 & * *\end{array}$

$\begin{array}{lllll}0.0545752 & 0.0160175 & 3.407 & 0.000827 & * * *\end{array}$

$\begin{array}{llllll}-0.1623406 & 0.0497016 & -3.266 & 0.001328 & * *\end{array}$

$\begin{array}{llll}-0.0447288 & 0.0199124 & -2.246 & 0.026029\end{array}$

$\begin{array}{lllll}-0.0123356 & 0.0061176 & -2.016 & 0.045398 *\end{array}$

$\begin{array}{llll}0.0390774 & 0.0252843 & 1.546 & 0.124159\end{array}$

$\begin{array}{llll}0.2830638 & 0.0953865 & 2.968 & 0.003454 \\ * *\end{array}$

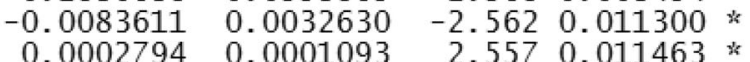

Multiple Regression 2

Ca11:

$1 \mathrm{~m}$ (formula = BoardingRate_pass_sec $\sim$ NumberofBoarders + A_X_B +

VestibuleLoad_pass + PercentagewithLuggage + Platformwidth_m +

Trainsteps_binary + InterDoorDistance_m + vestibulesize_m2 +

CarAreavsDoorwidth_m + DoorsPerCar, data = DB3BNoNA, na.action = na. exclude)

Residuals:

Min 10 Median $30 \quad$ Max
$-0.59201$
$-0.11708$
$-0.02191$
0.09962
0.55483

Coefficients:

\begin{tabular}{|c|c|c|c|c|c|}
\hline & Estimate & Std. Error & $\mathrm{t}$ value & $\operatorname{Pr}(>|t|)$ & \\
\hline (Intercept) & 0.7665698 & 0.1365390 & 5.614 & $8.13 e-08$ & k* \\
\hline NumberofBoarders & 0.0175669 & 0.0028383 & 6.189 & $4.57 e-09$ & $* * *$ \\
\hline$A \_X \_B$ & 0.0002685 & 0.0001083 & 2.479 & 0.014158 & * \\
\hline Vestibuleload_pass & -0.0126235 & 0025722 & -4.908 & $2.19 \mathrm{e}-06$ & \\
\hline PercentagewithLuggage & -0.0081635 & 0.0029204 & -2.795 & 0.005796 & ** \\
\hline PlatformWidth_m & 0.0611926 & 0163250 & 3.748 & 0.000245 & $* * *$ \\
\hline Trainsteps_biñary & -0.1574609 & 0.0500098 & -3.149 & 0.001946 & w. \\
\hline InterDoorDistance_m & -0.0158794 & 0.0061508 & & 0.010695 & $*$ \\
\hline Vestibulesize_m2 & 0.05 & 11 & 3.697 & 0.000296 & kwk \\
\hline CarAreaVsDoorwidth_m & -0 . & 18 & -1.663 & 0.098289 & \\
\hline DoorsPercar & -0.0348611 & 0.0205289 & -1.698 & 0.091354 & . \\
\hline
\end{tabular}

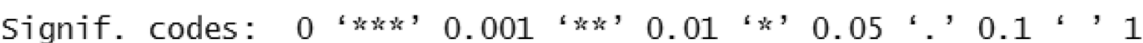

Residual standard error: 0.1951 on 166 degrees of freedom

Multiple R-squared: $0.675, \quad$ Adjusted R-squared: 0.6554

F-statistic: 34.48 on 10 and $166 \mathrm{DF}$, p-value: $<2.2 \mathrm{e}-16$ 
Multiple Regression 3

Ca11:

$1 \mathrm{~m}$ (formula $=$ BoardingRate_pass_sec $\sim$ NumberofBoarders_F + A_X_B_F +

VestibuleLoad_pass_F + PercentagewithLuggage_F + PlatformWidth_m_F +

Trainsteps_binary_F + InterDoorDistance_m_F + Standbackwidth_step_function_F + Vestibulesize_m2_F + AișlewidthNetofPeop1eFeet_m_F + SaloonExitDifficu1ty_F, data $=$ DB3BNoNA, na.action = na.exclude)

Residua1s:

Min 10 Median $30 \quad$ Max

$\begin{array}{lllll}-0.58590 & -0.12501 & -0.02285 & 0.11537 & 0.60912\end{array}$

Coefficients:

(Intercept)

NumberofBoarders_F

A_X_B_F

VestibuleLoad_pass_F

Percentagewi thLuggage_F

Platformwidth_m_F

Trainsteps_binary_F

InterDoorDistance_m_F

Standbackwidth_step_function_F

vestibulesize_m2 F

Ais lewidthNetofPeopleFeet_m_F

SaloonExitDifficulty_F

Estimate std.

Estimate std. Error $t$ value $\operatorname{Pr}(>|t|)$

$\begin{array}{llll}-1.2464 & 0.4151 & -3.002 & 0.003096\end{array}$ k*

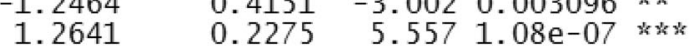

$\begin{array}{llll}0.4287 & 0.1707 & 2.511 & 0.013003\end{array}$

$\begin{array}{llll}0.3199 & 0.2298 & 1.392 & 0.165866\end{array}$

$\begin{array}{llll}0.3273 & 0.1653 & 1.980 & 0.049397\end{array}$

$\begin{array}{llll}0.4527 & 0.1807 & 2.506 & 0.013193\end{array}$ *

$\begin{array}{llll}0.3910 & 0.1055 & 3.707 & 0.000286\end{array}$ k*

$0.5684 \quad 0.1260 \quad 4.5131 .21 \mathrm{e}-05 * * *$

$\begin{array}{llll}0.2910 & 0.1956 & 1.488 & 0.138649\end{array}$

$\begin{array}{llll}0.2689 & 0.1203 & 2.235 & 0.026759\end{array}$

$\begin{array}{llll}-0.3320 & 0.1459 & -2.276 & 0.024135 *\end{array}$

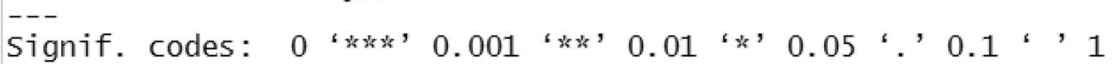

Residual standard error: 0.2141 on 165 degrees of freedom

Multiple R-squared: 0.6112 , Adjusted R-squared: 0.5852

F-statistic: 23.58 on 11 and $165 \mathrm{DF}$, p-value: $<2.2 \mathrm{e}-16$

Multiple Regression 4

Ca11:

$7 \mathrm{~m}$ (formu $7 \mathrm{a}=$ BoardingRate_pass_sec $\sim$ NumberofBoarders_F + A_X_B_F +

Vestibu 1eLoadVsCapacity_F + Boarders_in_xs_of_remaining_vest_cap_F +

Percentagewi thLuggage_F + PlatformWidth_m_F + verticalstepDist_mm_F + Trainsteps_binary_F + InterDoorDistance_m_F + Vestibulecapacity_pass_F, data $=$ DB3BNoNA, na. action = na. exclude)

Residuals:
Min
10 Median

$-0.59572-0.10504-0.02561$

$3 \mathrm{Q}$
0.10279

Max
0.68552

Coefficients:

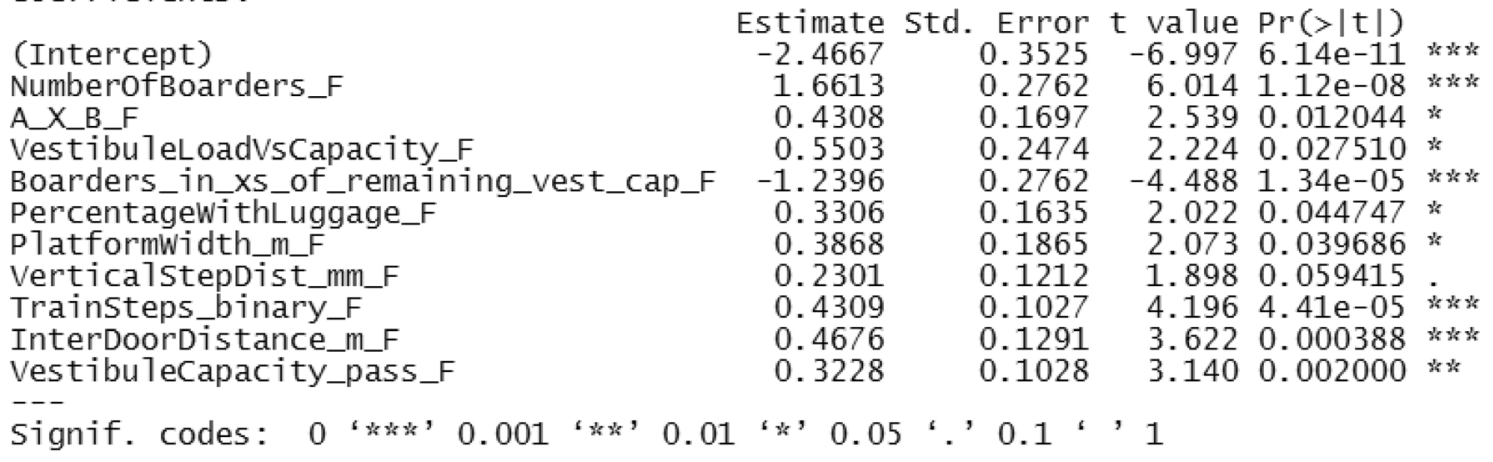

Residual standard error: 0.2108 on 166 degrees of freedom Mu7tiple R-squared: 0.6206 , Adjusted R-squared: 0.5978 F-statistic: 27.15 on 10 and $166 \mathrm{DF}$, p-value: $<2.2 \mathrm{e}-16$ 
Table 5 Correlation matrix for variables affecting boarding rate

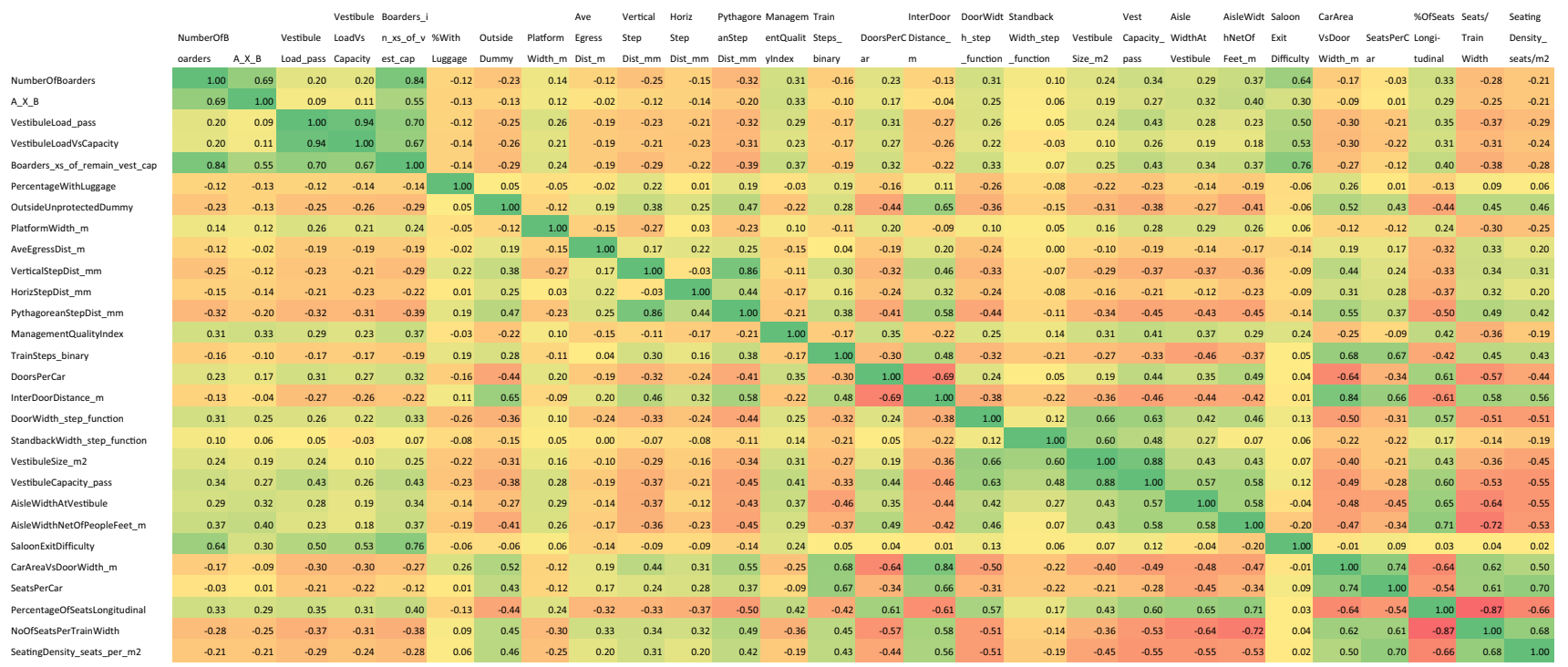

\subsection{Comparison of Models and Choice of the Best Model}

Three primary criteria were used to determine the model variant deemed to be the best:

(i) Significance of the entire regression and each independent variable

- The $F$-statistic is a test of significance for the entire regression. If the $p$-value of the $F$ statistic is $<\alpha$, the model is $\alpha$-significant. This means that at least one of the independent variables is significantly related to the outcome (or dependent) variable, being different from 0 .

- In terms of contribution of each of the independent variables in the prediction of the dependent variable, it is important to focus on the $t$-statistic and $p$-values of each independent variable.

\section{(ii) Model accuracy assessment}

The overall quality of the model can be assessed by examining the multiple $R$-squared $\left(R^{2}\right)$, adjusted $R$-squared and residual standard error (RSE).

- In multiple linear regression, the multiple $R$ squared represents the correlation coefficient between the observed values of the outcome variable $(y)$ and the fitted (i.e. predicted) values of $y$. It is a measure of the "explained variation' and provides the percentage of the total variation in alighting rate that is explained by the regression.

- The adjusted $R^{2}$ is a correction for the number of independent variables included in the prediction model. It is a measure of the percentage of the total variation in alighting rate that is explained by the regression, considering the number of independent variables included in the model.

- The RSE estimate gives a measure of error of prediction, or 'unexplained variation'. The lower the RSE, the more accurate the model.

\section{(iii) Variable coefficients}

The equation representing each model is:

$Y=\beta 1 X 1+\beta 2 X 2+\ldots+\beta n X n$

For a given independent variable, the coefficient can be interpreted as the average effect on the dependent variable of a one unit increase in the independent variable, holding all other independent variables fixed. The higher the absolute value of the coefficient, the stronger the influence of the independent variable on the dependent variable.

Also, a positive $\beta$ shows a directly proportional relationship between the dependent and independent variables, while a negative $\beta$ shows an inversely proportional relationship between the dependent and independent variables.

Alighters:

Table 6 shows the statistical results obtained for each model, indicating the following:

- The $p$-value of the $F$-statistic is $<2.2 \mathrm{e}-16$ for all models, which is highly significant. 
Table 6 Statistical analysis of alighting model variants

\begin{tabular}{|c|c|c|c|c|}
\hline Model & 1 & 2 & 3 & 4 \\
\hline Number of variables included & 34 & 18 & 18 & 28 \\
\hline Type of regression & Stepwise, linear & Stepwise, linear & Stepwise, polynomial & Stepwise, polynomial \\
\hline$p$-Value of the $F$-statistic & $<2.2 \mathrm{e}-16$ & $<2.2 \mathrm{e}-16$ & $<2.2 \mathrm{e}-16$ & $<2.2 \mathrm{e}-16$ \\
\hline$R$-squared & 0.6924 & 0.6072 & 0.5668 & 0.5972 \\
\hline Adjusted $R$-squared & 0.6711 & 0.5915 & 0.5494 & 0.5726 \\
\hline Standard error & 0.2592 & 0.2889 & 0.3034 & 0.2955 \\
\hline \multirow[t]{3}{*}{ Number of relevant variables for $\alpha=1$} & 11 & 9 & 8 & 12 \\
\hline & $32.4 \%$ & $50.0 \%$ & $44.4 \%$ & $42.9 \%$ \\
\hline & (11 out of 34$)$ & (9 out of 18$)$ & (8 out of 18$)$ & (12 out of 28$)$ \\
\hline \multirow[t]{3}{*}{ Number of relevant variables for $\alpha=0.1$} & 11 & 7 & 8 & 10 \\
\hline & $32.3 \%$ & $38.9 \%$ & $44.4 \%$ & $35.7 \%$ \\
\hline & (11 out of 34$)$ & (7 out of 18 ) & (8 out of 18$)$ & (10 out of 28$)$ \\
\hline \multirow[t]{3}{*}{ Number of relevant variables for $\alpha=0.05$} & 10 & 5 & 6 & 8 \\
\hline & $29.4 \%$ & $27.8 \%$ & $33.3 \%$ & $28.6 \%$ \\
\hline & (10 out of 34$)$ & (5 out of 18$)$ & (6 out of 18 ) & (8 out of 28$)$ \\
\hline \multirow[t]{3}{*}{ Number of relevant variables for $\alpha=0.01$} & 8 & 4 & 3 & 4 \\
\hline & $23.5 \%$ & $22.2 \%$ & $16.7 \%$ & $14.3 \%$ \\
\hline & ( 8 out of 34$)$ & (4 out of 18 ) & ( 3 out of 18 ) & (4 out of 28 ) \\
\hline \multirow[t]{3}{*}{ Number of relevant variables for $\alpha=0.001$} & 5 & 4 & 3 & 3 \\
\hline & $14.7 \%$ & $22.2 \%$ & $16.7 \%$ & $10.7 \%$ \\
\hline & (5 out of 34 ) & (4 out of 18 ) & ( 3 out of 18 ) & (3 out of 28 ) \\
\hline
\end{tabular}

- The $R^{2}$ values should not be compared among the models above, as they involve a different number of variables. To take into consideration the variables included in the linear models considered, the adjusted $R^{2}$ should be compared.

- The adjusted $R^{2}$ is generally very high, showing that, in all models, the total 'explained variation' in alighting rate is mostly explained by the regression, considering the number of independent variables included in the model. However, regression model 1 is characterised by the highest explained variation, meaning the 11 variables selected by the model are the ones that mostly explain the regression. Model 3 is characterised by the lowest explained variation.

- The 'unexplained variation' of the models is generally very low (in the range between 0.2592 and 0.3034 ), showing the error of prediction is very low and all models are quite accurate. Regression model 1 is the most accurate model, while model 3 is the least accurate model.

- Model 2 is characterised by the highest percentage of independent variables included in the model when the risk of not having a relationship between the dependent and independent variable is less than $0.1 \%(\alpha=0.001)$, this percentage being $22.2 \%$. This model is characterised by: linear function, 18 input variables, as selected based on the correlation matrix, and a stepwise regression selecting the most interesting variables among them. It is also efficient because it gets the second highest value of the adjusted $R$-squared with only 18 variables.

- Overall, model 2 is the best model, as it is characterised by the highest percentage of independent variables included in the model when the risk of not having a relationship between the dependent and independent variable is less than $0.1 \%(\alpha=0.001)$ and acceptable values of the adjusted $R^{2}$ and the standard error.

The equation of model 2 is shown below:

Alighting rate $=0.6302119+0.0252974$ NumberOfAlighters $-0.6645940 \quad$ VestibuleLoadVsCapacity -0.0120642 PercentageWithLuggage -0.1132247 OutsideUnprotectedDummy $+0.0407892 \quad$ PlatformWidth_m + 0.0005903HorizStepDist_mm + 0.1157983 DoorsPerCar - 0.0191556

InterDoorDistance_m

It shows the following: 
- As expected, the following functions are directly proportional to the alighting rate: number of alighters, platform width and doors per car.

- As expected, the following functions are inversely proportional to the alighting rate: vestibule load vs capacity, percentage with luggage, outside unprotected dummy and inter-door distance.

- The following function is directly proportional, but it was expected to be inversely proportional to the alighting rate: horizontal step distance. The results of a further investigation are shown below.

The horizontal step distance is represented as follows (Fig. 6):

The analysis of this variable is clearly affected by an outlier. The negative horizontal step distance $(-20 \mathrm{~mm})$ represents a location where the platform and train genuinely overlap. Although we could have deleted this outlier, in this case, the step distance was reset to zero, as the effective horizontal gap is zero (a vertical gap obviously remains). The corresponding $\beta$ obtained from the model is not very reliable $(\alpha=1)$, and the associated equation may not correctly represent the reality.

The values shown in the table above also suggest that a gap of $100 \mathrm{~mm}$ allows an alighting rate (equal to 1.17 passengers/s, on average) to be higher than the alighting rate associated with a distance of $50 \mathrm{~mm}$ (alighting rate equal to 1.11 passengers/s, on average). Whilst the alighting rate might theoretically be expected to decrease when the horizontal step distance increases, other researchers have also found a maximum passenger flow to occur with this size of gap.

At this stage, it was clear that we had a model with three very statistically significant variables (characterised by $\alpha=0.001$ ): NumberOfAlighters, VestibuleLoadVsCapacity and DoorsPerCar. However, a choice needed to be made between the different model formulations.

\section{Boarders:}

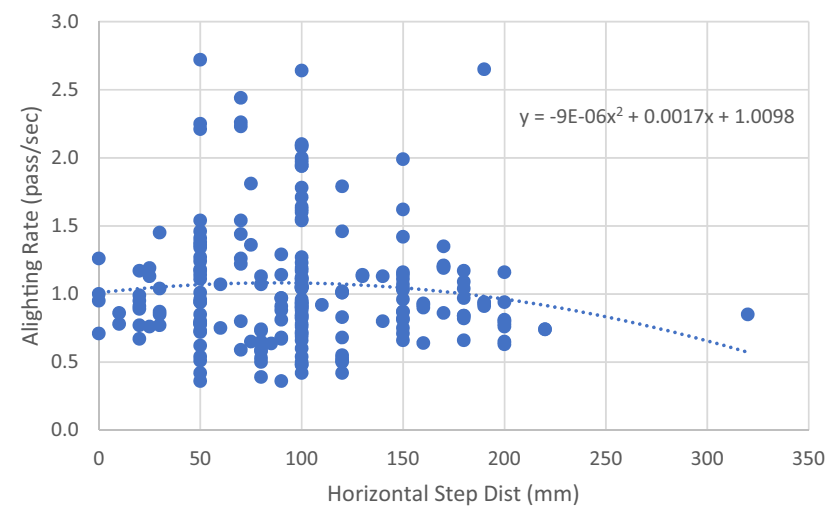

Fig. 6 Scattergram of alighting rate by horizontal stepping distance
Table 7 shows the results obtained for each model, indicating the following:

- The $p$-value of the $F$-statistic is $<2.2 \mathrm{e}-16$ for all models, which is highly significant.

- As before, a comparison on the adjusted $R^{2}$ values is appropriate, and these values are generally very high. This shows that, in all models, the total 'explained variation' in boarding rate is mostly explained by the regression, considering the number of independent variables included in the model. However, regression model 1 is characterised by the highest explained variation, meaning the 13 variables selected by the model are the ones that mostly explain the regression. Model 3 is characterised by the lowest explained variation.

- The 'unexplained variation' of the models is generally very low (in the range between 0.1888 and 0.2141 ), showing the error of prediction is very low and all models are quite accurate. Regression model 1 is the most accurate model, while model 3 is the least accurate model.

- Model 2 and model 3 are characterised by the highest percentage of independent variables included in the model when the risk of not having a relationship between the dependent and independent variable is less than $0.1 \%(\alpha=0.001)$, this percentage being $22.2 \%$. Model 2 is characterised by: linear function, 18 input variables, as selected based on the correlation matrix, and a stepwise regression selecting the most interesting variables among them. It is also efficient because it gets the second highest adjusted $R^{2}$ value with only 18 variables. Model 3 is characterised by: polynomial function, 18 input variables, as selected based on the correlation matrix, and a stepwise regression selecting the most interesting variables among them. Unfortunately, the adjusted $R$-squared associated to model 3 is the lowest one available.

- Overall, model 2 is the best model, as it is characterised by the highest percentage of independent variables included in the model when the risk of not having a relationship between the dependent and independent variable is less than $0.1 \%(\alpha=0.001)$ and acceptable values of the adjusted $R$-squared and the standard error.

The equation of model 2 is shown below:

Boarders rate $=0.7665698+0.0175669 \quad$ NumberOfBoarders +0.0002685 A_X_B -0.0126235 VestibuleLoad_pass - 0.0081635 PercentageWithLuggage $+0.0611926 \quad$ PlatformWidth_m -0.1574609 TrainSteps_Binary -0.0158794 
Table 7 Statistical analysis of boarding model variants

\begin{tabular}{|c|c|c|c|c|}
\hline Model & 1 & 2 & 3 & 4 \\
\hline Number of variables included & 34 & 18 & 18 & 28 \\
\hline Type of regression & Stepwise, linear & Stepwise, linear & Stepwise, polynomial & Stepwise, polynomial \\
\hline$p$-Value of the $F$-statistic & $<2.2 \mathrm{e}-16$ & $<2.2 \mathrm{e}-16$ & $<2.2 \mathrm{e}-16$ & $<2.2 \mathrm{e}-16$ \\
\hline$R$-squared & 0.7013 & 0.675 & 0.6112 & 0.6206 \\
\hline Adjusted $R$-squared & 0.6775 & 06554 & 0.5852 & 0.5978 \\
\hline Standard error & 0.1888 & 0.1951 & 0.2141 & 0.2108 \\
\hline \multirow[t]{3}{*}{ Number of relevant variables for $\alpha=1$} & 13 & 10 & 11 & 10 \\
\hline & $38.2 \%$ & $55.6 \%$ & $61.1 \%$ & $35.7 \%$ \\
\hline & (13 out of 34$)$ & (10 out of 18$)$ & (11 out of 18$)$ & (10 out of 28$)$ \\
\hline \multirow[t]{3}{*}{ Number of relevant variables for $\alpha=0.1$} & 11 & 10 & 9 & 10 \\
\hline & $32.4 \%$ & $55.5 \%$ & $50 \%$ & $35.7 \%$ \\
\hline & (11 out of 34$)$ & (10 out of 18$)$ & ( 9 out of 18$)$ & (10 out of 28$)$ \\
\hline \multirow[t]{3}{*}{ Number of relevant variables for $\alpha=0.05$} & 11 & 8 & 9 & 9 \\
\hline & $32.4 \%$ & $44.4 \%$ & $50 \%$ & $32.1 \%$ \\
\hline & (11 out of 34$)$ & (8 out of 18$)$ & (9 out of 18$)$ & (9 out of 28 ) \\
\hline \multirow[t]{3}{*}{ Number of relevant variables for $\alpha=0.01$} & 6 & 6 & 4 & 5 \\
\hline & $17.6 \%$ & $33.3 \%$ & $22.2 \%$ & $17.9 \%$ \\
\hline & $(6$ out of 34$)$ & ( 6 out of 18$)$ & (4 out of 18 ) & (5 out of 28$)$ \\
\hline \multirow[t]{3}{*}{ Number of relevant variables for $\alpha=0.001$} & 1 & 4 & 4 & 4 \\
\hline & $2.9 \%$ & $22.2 \%$ & $22.2 \%$ & $14.3 \%$ \\
\hline & (1 out of 34$)$ & (4 out of 18 ) & (4 out of 18 ) & (4 out of 28 ) \\
\hline
\end{tabular}

InterDoorDistance_m $+0.0562685 \quad$ VestibuleSize_m2 - $0.0055227 \quad$ CarAreaVsDoorWidth_m 0.0348611 DoorsPerCar

It shows the following:

- As expected, the following functions are directly proportional to the alighting rate: number of boarders, platform width, vestibule size.

- As expected, the following functions are inversely proportional to the alighting rate: vestibule load per passenger, percentage of passengers with luggage, train steps_binary, inter-door distance, car area vs door width.

- The A_X_B function was found to be directly proportional with passenger flow, but was expected to be inversely proportional, reflecting increased boarding difficulty when there are many alighters. However, an alternative hypothesis is that a greater number of alighters creates more room for boarders to enter, so this latter hypothesis may indeed be more appropriate.

- The following function is inversely proportional, but it was expected to be directly proportional to the boarding rate: doors per car. This variable requires further investigation (Fig. 7).

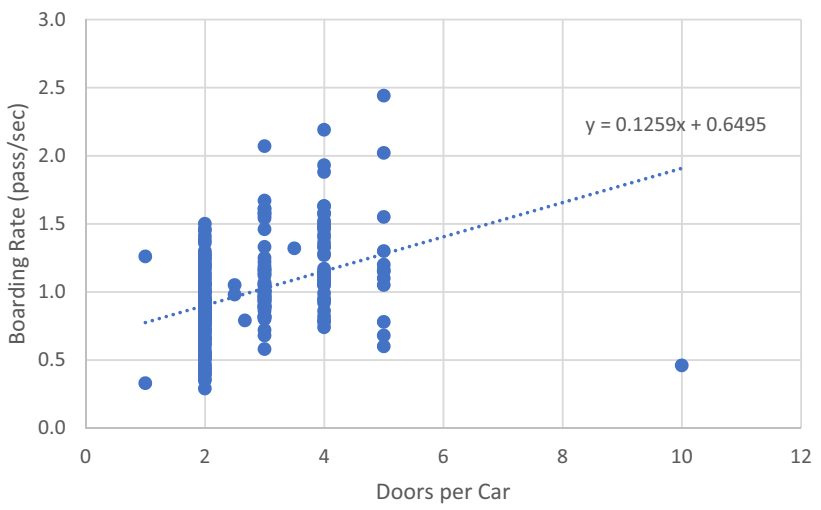

Fig. 7 Scattergram of boarding rate by number of doors per car

Further investigation should include the outlier in this data set. Ten doors per car are associated with a boarding rate of 0.46 passengers/s, which is the lowest value present in the table above. It might therefore consequently be considered an outlier and removed. In general, the boarding rate would be expected to increase when the number of doors per car increases. However, it does relate to a genuine type of British train (now scrapped): VEP (Vestibuled Electro-Pneumatic brake) train sets on train services south of London were one of several types in which slam doors were fitted to every seating bay (Fig. 8). This minimised 


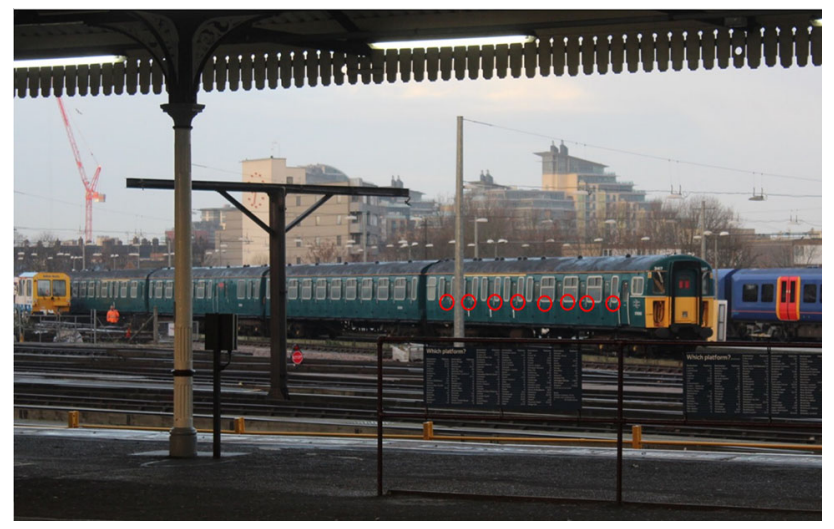

Fig. 8 Preserved VEP at Clapham Junction. Source The separate door handles for each seating bay are just visible, as shown those red circled in Fig. 8

the number of passenger movements per door, which is perhaps the most critical variable, but management of which effectively precedes all the analysis shown in this paper. However, the lack of space between passengers sitting opposite each other meant that there was effectively no aisle space, and boarders/alighters had to be careful (hence the rate of passenger movement was much slower) in ensuring that they were not standing on the feet of other passengers.

It is possible that the curve might become stable (but not decrease) when the number of doors is bigger than a certain threshold (which, in this case, corresponds to 3.5 doors). However, whilst included within the stepwise regression, the corresponding $\beta$ obtained from the model is not very reliable $(\alpha=0.1)$, so the associated equation may not correctly represent reality.

That model is based on the following variables as the most statistically significant (and characterised by $\alpha=0.001$ ): number of boarders, VestibuleLoad_pass, PlatformWidth_m, VestibuleSize_m2. The best models provided have been used to proceed with the disaggregation by type of railway (differentiating between alighters and boarders), conscious that some variables are more statistically significant than others (as they are characterised by $\alpha=0.001$ ).

\subsection{Interpretation of Results}

\subsubsection{Alighting}

Model 2 is therefore regarded as the best model, giving

Alighting rate (passengers $/ \mathrm{s})=0.63+0.025$ alighters -0.66 vest load/capacity $-0.012 \%$ pass with luggage -0.113 outside dummy +0.04 platform width $(\mathrm{m})+0.0006$ horiz step dist $(\mathrm{mm})+0.116$ doors/car 0.019 inter-door distance (the detailed statistics associated with this are shown in Sect. 5.1, above).

For a typical situation with 10 people boarding through the vestibule $10 \%$ full, $5 \%$ of passengers having luggage, an 'outside' platform $3 \mathrm{~m}$ wide, a train-platform gap of $100 \mathrm{~mm}$ and a train with 2 doors/car, $10 \mathrm{~m}$ apart, the forecast alighting rate would $\mathrm{be}=0.63+0.25-0.07-0.06-0.11+0.12+0.06$ $+0.23-0.19=0.86$ passengers/s.

All the variables are as expected, with the exception of the horizontal stepping distance where (as discussed in Sect. 3.3 above) previous research findings have varied widely, and there is (as yet) no consensus as to the underlying theoretical basis for any hypothesis.

\subsubsection{Boarding}

Model 2 is again regarded as the best model, giving

Boarding rate (passengers $/ \mathrm{s})=0.77+0.017$ boarders $+0.0003(\mathrm{AxB})-0.13$ vestibule load $-0.008 \%$ with luggage +0.06 platform width $(\mathrm{m})-0.16$ if train steps -0.016 inter-door distance +0.056 vestibule area -0.006 car area/door width -0.035 doors/car

For a typical situation with 10 people boarding (of which $10 \%$ have luggage) whilst 10 alight and 5 remain in the vestibule, a platform $3 \mathrm{~m}$ wide and a train with no steps, 2 doors/car, $10 \mathrm{~m}$ apart, a vestibule area of $10 \mathrm{~m}^{2}$ and a total car area of $60 \mathrm{~m}^{2}$, the forecast boarding rate would be $=0.77+0.18+0.03-0.06-0.08+0.18-0-$ $0.16+0.56-0.33-0.07=1.12$ passengers $/$ s.

Again, all the results are as expected, bar one. Here, it is the 'doors per car' variable which is not directly intuitive: one would expect more doors per car to reduce access times to, and queuing in, doorways, and hence increasing passenger movement rates. As the model also includes the variable 'car area per door width' (if only significant at 95\%), we suspect that the 'doors per car' variable is actually acting as a proxy for more crowded urban environments, since it is in such places that train operators employ rolling stock with more doors. This hypothesis is supported by the disaggregation of results by type of railway (see Sect. 6), where this variable only occurs with this sign in the highest-frequency metro environment, and is of the opposite sign in the medium-frequency category.

Several of the variables produce results which are directly comparable with movement rates quoted by other authors. In terms of luggage, the limitation of 'luggage' to large items, and the train types involved may explain some of the differences (in particular, steps are of greater impediment to passengers with luggage), but these recent results are in the upper half of other research. 
Table 8 Comparison of selected variable-level results with those of other authors

\begin{tabular}{llll}
\hline Variable & Author & Their result & Regression result \\
\hline Large luggage & Holloway et al. [37] & $-5 \%$ & -80 to 120\% \\
& Harris and Ehizele [29] & -10 to $-80 \%$ & \\
& Weidmann [42] & Up to $-200 \%$ & \\
No. of vestibule passengers & Palmqvist et al. [25] & 0.08 s/standee & -0.007 per \% (alighting)/-0.013 passengers/s (boarding)
\end{tabular}

If one assumes a maximum vestibule capacity of 25 passengers and a typical passenger movement rate of 1 passenger/s, then our results for boarding closely match those of Palmqvist et al. [25], but are higher for alighting (since each extra person in the vestibule takes up about $4 \%$ [100\%/25] of its space). Other variables previously found to be statistically significant (e.g. standback width) have not provided such results here (Table 8).

In order to put impacts into perspective, Table 9 below sets out the measures which might be taken by a train operator or infrastructure company to increase passenger movement rates by $10 \%$. This gets away from the trying to compare the parameter values of the model directly (since these are determined by the units of measurement) and helps to understand the real impacts of the results, for practical application: some variables are simply more easily amended by $10 \%$ than others. In these calculations, we have assumed typical movements of 10 alighters or boarders, and vestibules with a maximum capacity of 25 passengers.

Two of the values are slightly counter-intuitive. The regression parameter for horizontal stepping distance is positive, but only slightly, and the parameter is small; there is some evidence (e.g. see Fig. 6) that, whilst small horizontal gaps are indeed of negligible impact on passenger flows, larger ones have more severe negative impacts. Whilst one might have thought that increasing gaps would lead to decreasing flows, these results could possibly reflect the (delay of the) mental decision required with very small gaps, when for some people it could be possible to step on the platform and the train simultaneously.

The negative parameter for the 'doors per car' variable for boarding is thought to be reflecting the more crowded conditions in which train operators choose vehicle designs with more doors. It is not recommended that railway companies reduce the number of doors per car, although Heinz [9] did demonstrate that it is the total amount of door width/car (area), rather than the width of each individual door, which is important.

\subsection{Comparison with Previous Models}

The output from the 2014 model has been widely used commercially, for instance in the scoring of bids for rolling stock tenders for new trains. It therefore seemed appropriate to see whether the latest analysis was producing similar results and hence similar appraisals of specific situations. The parameter values are compared in Table 10. Note that some variables have been consistently included with similar parameter values, whilst others have entered the model or been dropped from it as the database has been expanded.

Re-estimation with a larger data set seems to have had several effects, including the following:

(i) confirmation of parameters and their values (e.g. platform width for boarding, was 0.056, now $0.061)$;

(ii) confirmation of concepts but measured slightly differently (e.g. total vestibule size now being preferred to explain boarding rates, rather than just the standback);

(iii) new variables genuinely adding value (e.g. the \% of passengers with heavy luggage).

The level of explanation in the model, as measured by $R^{2}$, is broadly the same.

Analysis of a range of rolling stock designs proposed in a European country showed that the results for alighting rates from this model were extremely similar to the previous one, but those for boarding were $10 \%+$ higher, largely due to a better understanding of the impact of large vestibules.

\subsection{Discarded Variables}

In Sect. 4.5, we set out our approach for finding the best model, an approach which started by including all 34 variables for which data was available. However, a few variables did not provide any statistical explanation at all, and were therefore excluded from further analysis. Some of the variables were different functions relating to the same underlying concept, so it was an advantage in being able to 
Table 9 Actions needed to increase passenger movement rates

\begin{tabular}{|c|c|c|c|c|c|}
\hline \multirow[t]{2}{*}{ Variable } & \multicolumn{2}{|c|}{ Parameter values } & \multicolumn{2}{|c|}{$\begin{array}{l}\text { Action needed to increase rate } \\
\text { by } 10 \%\end{array}$} & \multirow[t]{2}{*}{ Notes } \\
\hline & Alighting & Boarding & Alighting & Boarding & \\
\hline $\begin{array}{l}\text { Number of alighters/ } \\
\text { boarders per door }\end{array}$ & 0.025 & 0.018 & \multicolumn{2}{|c|}{-0.98 passengers } & $\begin{array}{l}\text { Net effect of reducing the number of passengers (e.g. by } \\
\text { spreading them out across more doors/train services, } \\
\text { by management and information means as well as } \\
\text { physically), offset by the slower per-person movement } \\
\text { of a smaller no. of people }\end{array}$ \\
\hline $\begin{array}{l}\text { Product of } \\
\quad \text { (alighters } \times \text { boarders) } \\
\text { at critical door }\end{array}$ & & 0.0003 & & $\begin{array}{l}19 \text { fewer } \\
\text { alighters \& } \\
19 \text { fewer } \\
\text { boarders }\end{array}$ & \\
\hline $\begin{array}{r}\text { Vestibule load } \\
\text { (passengers) }\end{array}$ & & -0.126 & & $\begin{array}{l}0.8 \text { fewer } \\
\text { passengers in } \\
\text { vestibule }\end{array}$ & $\begin{array}{l}\text { Ensure that new/refurbished metro rolling stock has } \\
\text { adequate vestibule space; declutter aisles and reduce } \\
\text { vestibule occupancy e.g. by encouraging passengers to }\end{array}$ \\
\hline Vestibule load/Capacity & -0.665 & & $\begin{array}{l}3 \text { fewer } \\
\text { passengers } \\
\text { in vestibule }\end{array}$ & & seek out seats in mainline conditions \\
\hline Vestibule size $\left(\mathrm{m}^{2}\right)$ & & 0.056 & & $\begin{array}{l}\text { Increase by } \\
1.8 \mathrm{~m}^{2}\end{array}$ & \\
\hline Large luggage & -0.012 & -0.008 & $\begin{array}{l}8 \% \text { fewer } \\
\text { passengers } \\
\text { with } \\
\text { luggage }\end{array}$ & $\begin{array}{l}12 \% \text { fewer } \\
\text { passengers } \\
\text { with luggage }\end{array}$ & Ensure sufficient easily accessible luggage space \\
\hline Being outside & -0.113 & & $\begin{array}{r}\text { Make } 90 \% \\
\text { enclosed }\end{array}$ & & Protect platforms from adverse weather \\
\hline Platform width (m) & 0.041 & 0.061 & $\begin{array}{l}\text { Increase by } \\
2.5 \mathrm{~m}\end{array}$ & $\begin{array}{l}\text { Increase by } \\
1.5 \mathrm{~m}\end{array}$ & $\begin{array}{l}\text { May be achievable through removal of platform } \\
\text { furniture, as well as widening the platform itself }\end{array}$ \\
\hline $\begin{array}{l}\text { Horizontal stepping } \\
\text { distance }(\mathrm{mm})\end{array}$ & 0.0006 & & (see text) & & \\
\hline Train steps & & -0.157 & & $\begin{array}{l}\text { Removal saves } \\
\quad \text { c. } 15 \%\end{array}$ & $\begin{array}{l}\text { Steps in train doorways to be eliminated wherever } \\
\text { possible on mobility grounds: these results show the } \\
\text { impact on able-bodied people }\end{array}$ \\
\hline Doors per car & 0.116 & -0.035 & $\begin{array}{l}\text { Adding a } \\
\text { door saves } \\
12 \%\end{array}$ & $($ see text $)$ & $\begin{array}{l}\text { Consider more doors/car or shorter 2-door cars: } 2 \text { doors } \\
\text { OK in cars approx. } 20 \mathrm{~m} \text { long, but probably not for } \\
\text { longer vehicles }\end{array}$ \\
\hline Inter-door distance (m) & -0.019 & -0.016 & $\begin{array}{l}\text { Reduce by } \\
0.5 \mathrm{~m}\end{array}$ & $\begin{array}{l}\text { Reduce by } \\
0.7 \mathrm{~m}\end{array}$ & \\
\hline $\begin{array}{l}\text { Car area per door width } \\
(\mathrm{m})\end{array}$ & & -0.0055 & & $\begin{array}{l}\text { Reduce by } \\
\qquad 18 \mathrm{~m}\end{array}$ & \\
\hline
\end{tabular}

select one variant. Nevertheless, two variables were excluded entirely, and are worthy of particular comment.

The use of a double-sided platform has long been regarded by metro engineers and operators as a positive contributor to minimising station stop times, on the basis of minimising the interactions between alighting and boarding passengers. We have not managed to demonstrate that, possibly through the small number of observations with it (11). An alternative explanation for this might be the difficulty of including within the model two different door opening times: it is common practice at such locations to open the door for alighting first, and only to open the door for boarders when alighting is largely complete.

The use of platform edge/screen doors has been posited in previous research both to reduce and to increase passenger flow rates. Single-variable analysis suggests a positive coefficient of 0.3 for both alighting and boarding, but multi-variable analysis here shows that we cannot identify any impact to be statistically significantly different from zero when other variables are included.

Several variables have not 'made the cut' into the final smaller models, in order to satisfy statistical efficiency tests. Nevertheless, it is worth noting their continuing 
Table 10 Comparison of previous and current model parameters

\begin{tabular}{|c|c|c|c|c|}
\hline \multirow[t]{2}{*}{ Variable } & \multicolumn{2}{|l|}{ Alighting } & \multicolumn{2}{|l|}{ Boarding } \\
\hline & Previous model & Latest model & Previous model & Latest model \\
\hline Constant & 1.15 & 0.63 & 0.093 & 0.767 \\
\hline Alighters & & 0.025 & & \\
\hline Alighters^ ${ }^{\wedge} .8$ & 0.0601 & & & \\
\hline Boarders & & & 0.0182 & 0.0175 \\
\hline Alighters x Boarders product & & & & 0.0002 \\
\hline Alighters:Boarders ratio & 0.0127 & & 0.0048 & \\
\hline$\%$ of passengers with luggage & & -0.012 & & -0.008 \\
\hline Ratio of through passenger: capacity & -0.601 & -0.665 & & -0.013 \\
\hline (Ratio of through passenger: capacity)^1.6 & & & -0.359 & \\
\hline Two-sided platform (D) & 0.428 & & & \\
\hline Platform width (m) & & 0.041 & 0.056 & 0.061 \\
\hline Outside platform (D) & & -0.113 & & \\
\hline Vertical distance (mm) & -0.00129 & & & \\
\hline Horizontal distance (mm) & & 0.0006 & & \\
\hline Steps in vestibule (D) & & & -0.491 & -0.157 \\
\hline Doors per car & & 0.116 & & -0.035 \\
\hline Inter-door distance (m) & -0.0243 & -0.0191 & & -0.0159 \\
\hline Car area/door width (/m) & & & & -0.0055 \\
\hline $0.1 *$ Car area/door width $(/ \mathrm{m})^{\wedge}-0.5$ & & & 0.808 & \\
\hline Vestibule size $\left(\mathrm{m}^{2}\right)$ & & & & 0.056 \\
\hline Standback (m) & & & 0.261 & \\
\hline Seating density $\left(/ \mathrm{m}^{2}\right)$ & -0.164 & & & \\
\hline$R^{2}$ & 0.70 & 0.59 & 0.61 & 0.65 \\
\hline
\end{tabular}

$\mathrm{D}=$ dummy variable. Note that empty cells reflect relationships not found to be statistically significant

contribution towards passenger flow, and rolling stock manufacturers and train operators should still bear these factors in mind when developing new rolling stock types or refurbishing existing ones.

\section{Conclusions and Recommendations}

This paper reports the statistical meta-analysis of passenger alighting and boarding rates from a large international data set of over 200 surveys reflecting over 6000 measurements of individual trains. Data was available for 34 different variables, reflecting characteristics of passenger flow, rolling stock design, infrastructure and management. Single-variable regressions produce statistically significant coefficients for most of these, giving guidance to train specifiers, designers and operators.

A methodology has been developed which has been tested, works well with the data provided and can be repeated with a different data set. A stepwise regression method using the $R$ statistical package was then used to develop a more tractable model with fewer variables. This process eliminated those variables shown to provide no statistical explanation (including the presence of platform edge doors). Of the remaining 18 hypothesised variables, all provided some form of statistical explanation at the $90 \%$ level (or more) in one model or another.

The method has enabled the analysis of an international data set to determine the factors most influential in affecting the rates at which passengers alight from and board trains. The resulting relationships are as follows:

$$
\begin{aligned}
& \text { Alighting rate }=0.6302119+0.0252974 \text { NumberOfA- } \\
& \text { lighters - } 0.6645940 \quad \text { VestibuleLoadVsCapac- } \\
& \text { ity }-0.0120642 \text { PercentageWithLuggage }-0.1132247 \\
& \text { OutsideUnprotectedDummy + } 0.0407892 \text { Plat- } \\
& \text { formWidth_m + 0.0005903HorizStepDist_mm + } \\
& 0.1157983 \quad \text { DoorsPerCar - } 0.0191556 \\
& \text { InterDoorDistance_m } \\
& \text { Boarding rate (passengers } / \mathrm{s})=0.77+0.017 \text { board- }
\end{aligned}
$$


Table 11 Summary of variables and evidence found: alighting rates

\begin{tabular}{|c|c|c|c|}
\hline Variable & Hypothesis & Typical range of coefficients found for alighting & Comments \\
\hline Number of alighters/door & $+\mathrm{ve}$ & $0.025-0.03$ & \\
\hline Boarding: alighting ratio & $+\mathrm{ve}$ & $0.013-0.017$ & Never statistically significant \\
\hline Alighters $\times$ boarders & $+\mathrm{ve}$ & -0.001 to 0.001 & \\
\hline Vestibule load & $-\mathrm{ve}$ & -0.005 & Never statistically significant \\
\hline Vestibule load/capacity (\%) & $-\mathrm{ve}$ & -0.06 to -0.66 & Varies considerably \\
\hline Alighters in excess of capacity & $-\mathrm{ve}$ & 0.019 & \\
\hline$\%$ Passengers with luggage & $-\mathrm{ve}$ & -0.012 to -0.025 & \\
\hline Management quality index & $+\mathrm{ve}$ & 0.11 & \\
\hline Outside protection & $+\mathrm{ve}$ & -0.4 to -0.11 & \\
\hline Double-sided platform & $+\mathrm{ve}$ & $0.19-0.43$ & Never statistically significant \\
\hline Platform screen doors & - ve & 0.31 & \\
\hline Platform width (m) & $+\mathrm{ve}$ & $0.04-0.11$ & \\
\hline Egress distance $(\mathrm{m})$ & - ve & -0.05 to -0.002 & \\
\hline Vertical step distance (mm) & $-\mathrm{ve}$ & -0.002 to -0.001 & \\
\hline Horizontal step distance $(\mathrm{mm})$ & $-\mathrm{ve}$ & -0.0005 to 0.0015 & \\
\hline Pythagorean step distance & - ve & -0.002 & \\
\hline Double-deck & $-\mathrm{ve}$ & 0.04 & Never statistically significant \\
\hline Train steps (no.) & $-\mathrm{ve}$ & -0.05 & Never statistically significant \\
\hline Train steps (D) & $-\mathrm{ve}$ & -0.32 & \\
\hline Doors per car & $+\mathrm{ve}$ & $0.12-0.23$ & \\
\hline Inter-door distance (m) & $-\mathrm{ve}$ & -0.035 to -0.024 & \\
\hline Door width (m) & +ve, not linear & 0.49 & \\
\hline Door width category & $+\mathrm{ve}$ & 0.26 & \\
\hline Standback width (m) & +ve, not linear? & 0.13 & Never statistically significant \\
\hline Standback width category & $+\mathrm{ve}$ & -0.05 & \\
\hline Grab poles (D) & $-\mathrm{ve}$ & 0.06 & Never statistically significant \\
\hline Vestibule size $\left(\mathrm{m}^{2}\right)$ & $+\mathrm{ve}$ & 0.1 & \\
\hline Vestibule capacity & $+\mathrm{ve}$ & 0.02 & \\
\hline Aisle width at vestibule & $+\mathrm{ve}$ & 0.36 & \\
\hline Aisle width saloon (m) & $+\mathrm{ve}$ & 0.51 & \\
\hline Saloon exit difficulty & $-\mathrm{ve}$ & 0.009 & \\
\hline Car area $\left(\mathrm{m}^{2}\right)$ & unclear & 0.002 & Never statistically significant \\
\hline Car area/door width & - ve & -0.017 & \\
\hline$\%$ longitudinal & $+\mathrm{ve}$ & 0.004 & \\
\hline Seats/car & $-\mathrm{ve}$ & -0.004 & \\
\hline Seats/train width & $-\mathrm{ve}$ & -0.14 & \\
\hline Seating density & $-\mathrm{ve}$ & -0.73 to -0.16 & \\
\hline
\end{tabular}

$\mathrm{D}=$ dummy variable. Entries in bold are statistically significant at $99 \%$

steps -0.016 inter-door distance +0.056 vestibule area -0.006 car area/door width -0.035 doors/car

Tables summarising the variables tested and their significance in different models are shown below. Where we have never achieved statistical significance for a variable across multiple model types, we nevertheless thought it would be helpful (for completeness) to provide some form of estimate, shown with a note in italics. These are based on:

(a) estimates from the 2014 model;

(b) estimates from single-variable analysis;

(c) non-statistically significant parameter values from the main analysis here (Tables 11 and 12). 
Table 12 Summary of variables and evidence found: boarding rates

\begin{tabular}{|c|c|c|c|}
\hline Variable & Hypothesis & Typical range of coefficients found for boarding & Comments \\
\hline Number of boarders/door & + ve & $\mathbf{0 . 0 1 7 - 0 . 0 2 7}$ & \\
\hline Boarding: alighting ratio & $+\mathrm{ve}$ & $0.003-0.005$ & \\
\hline Alighters $\times$ boarders & $+\mathrm{ve}$ & 0.0009 & \\
\hline Vestibule load & $-\mathrm{ve}$ & -0.13 to -0.004 & \\
\hline Vestibule load/capacity (\%) & $-\mathrm{ve}$ & 0.12 & \\
\hline Boarders in excess of capacity & $-\mathrm{ve}$ & 0.015 & \\
\hline$\%$ Passengers with luggage & $-\mathrm{ve}$ & -0.019 to -0.008 & \\
\hline Management quality index & $+\mathrm{ve}$ & $0.08-0.36$ & \\
\hline Outside protection & + ve & -0.38 & \\
\hline Double-sided platform & $+\mathrm{ve}$ & 0.004 & Never statistically significant \\
\hline Platform screen doors & - ve & 0.31 & \\
\hline Platform width (m) & $+\mathrm{ve}$ & $0.06-0.1$ & \\
\hline Egress distance $(\mathrm{m})$ & $-\mathrm{ve}$ & -0.002 & Never statistically significant \\
\hline Vertical step distance (mm) & $-\mathrm{ve}$ & -0.0017 & \\
\hline Horizontal step distance $(\mathrm{mm})$ & - ve & -0.0013 & Never statistically significant \\
\hline Pythagorean step distance & - ve & -0.0023 & \\
\hline Double-deck & $-\mathrm{ve}$ & -0.043 & Never statistically significant \\
\hline Train steps (no.) & - ve & -0.16 to -0.09 & \\
\hline Train steps (D) & $-\mathrm{ve}$ & -0.49 to -0.43 & \\
\hline Doors per car & $+\mathrm{ve}$ & -0.035 to 0.13 & \\
\hline Inter-door distance (m) & $-\mathrm{ve}$ & -0.16 to 0.035 & \\
\hline Door width (m) & +ve, not linear & 0.54 & \\
\hline Door width category & $+\mathrm{ve}$ & 0.28 & \\
\hline Standback width (m) & +ve, not linear? & $0.26-0.51$ & \\
\hline Standback width category & $+\mathrm{ve}$ & 0.14 & \\
\hline Grab poles (D) & $-\mathrm{ve}$ & -0.08 & Never statistically significant \\
\hline Vestibule size $\left(\mathrm{m}^{2}\right)$ & $+\mathrm{ve}$ & $0.056-0.14$ & \\
\hline Vestibule capacity & $+\mathrm{ve}$ & 0.022 & \\
\hline Aisle width at vestibule & $+\mathrm{ve}$ & 0.34 & \\
\hline Aisle width saloon (m) & $+\mathrm{ve}$ & 0.47 & \\
\hline Saloon exit difficulty & $-\mathrm{ve}$ & 0.005 & \\
\hline Car area $\left(\mathrm{m}^{2}\right)$ & Unclear & -0.002 & Never statistically significant \\
\hline Car area/door width & - ve & -0.006 to 0.018 & \\
\hline$\%$ longitudinal & $+\mathrm{ve}$ & 0.004 & \\
\hline Seats/car & $?$ & -0.005 & \\
\hline Seats/train width & $-\mathrm{ve}$ & -0.15 & \\
\hline Seating density & $-\mathrm{ve}$ & -0.61 & \\
\hline
\end{tabular}

$\mathrm{D}=$ dummy variable. Entries in bold are statistically significant at $99 \%$ 
However, in summary, the preferred models demonstrated passenger alighting rates to be primarily a function of:

- the number of alighters;

- vestibule load/capacity;

- $\%$ of passengers with luggage;

- whether or not the platform is unprotected from the weather;

- platform width;

- the horizontal stepping distance between the platform and the train;

- the number of doors per carriage; and

- the distance between those doors.

Those variables shown in bold have the greatest statistical significance. The positive parameter for horizontal stepping distance appears to be counter-intuitive, but is small and also reflects values found by other researchers.

Passenger boarding rates are primarily a function of:

- the number of boarders;

- the product of the number of alighters and the number of boarders;

- the vestibule load (passengers who neither alight nor board);

- $\%$ of passengers with luggage;

- platform width;

- vestibule size;

- whether there are any steps in the train doorway;

- the number of doors per carriage;

- the distance between those doors; and

- the ratio of car area to door width.

Again, those shown in bold have the greatest statistical significance.

In terms of future work, the database used should be increased in size to obtain more reliable results, especially for some of the more disaggregated analyses (e.g. by type of railway), where fewer data points are available in each category. Specific issues are worthy of further attentionfor instance, the use of platform screen doors and doublesided platforms, both of which features have historically been understood to be helpful to passenger movement rates, but which have not been proven here. Nevertheless, many of the variables shown as statistically significant for the entire data set also feature in disaggregated models, and with similar parameter values. Others would not necessarily be expected to provide the same level of explanatory power in subsets of the data, if they are inherently less important (e.g. heavy luggage is proportionately more important for longer-distance rail journeys).

\section{Appendix A: Single-Variable Relationships}

Alighters:

1. NumberOfAlighters_F $<-0.6045 *(\mathrm{DB} 3 \mathrm{~A} \$$ NumberOf Alighters^ 0.2451 )

2. A_X_B_F $<-0.5633 *\left(\mathrm{DB} 3 \mathrm{~A} \$ \mathrm{~A} \_\mathrm{X} \_\mathrm{B}^{\wedge} 0.1323\right)$

3. VestibuleLoad_pass_F $<-(-0.0007 *(\mathrm{DB} 3 \mathrm{~A} \$$ Vestibu leLoad_pass^2) $+(0.0165 *$ DB3A\$VestibuleLoad_ pass) +1.0273

4. VestibuleLoadVsCapacity_F $<-(-0.6177 *(\mathrm{DB} 3 \mathrm{~A} \$$ VestibuleLoadVsCapacity^2)) $+(0.2791 *$ DB3A\$ VestibuleLoadVsCapacity) +1.0473

5. Alighters_in_xs_of_remaining_vest_cap_F $<-(-0.0$ $0002 *(D B 3 A \$ A l i g h t e r s$ in_xs_of_remaining_vest_cap $\left.\left.^{\wedge} 3\right)\right)+(0.0012 *($ DB3A $\$$ Alighters_in_xs_of_remaining_vest_cap^2) $+(0.0044 *$ DB3A $\$$ Alighte rs_in_xs_of_remaining_vest_cap) +0.8497

6. PercentageWithLuggage_F $<-\left(-0.025^{*}\right.$ DB3A\$Pe rcentageWithLuggage $)+1.1912$

7. OutsideUnprotectedDummy_F $<-(-0.4008 *$ Outside UnprotectedDummy) +1.1633

8. PlatformWidth_m_F $<-\quad\left(0.1121^{*} \quad\right.$ DB3A $\$$ PlatformWidth_m) +0.671

9. AveEgressDist_m_F $<-(-0.0023 *$ DB3A $\$$ AveEgr essDist_m) +1.1733

10. VerticalStepDist_mm_F $<-(-0.000006 *(\mathrm{DB} 3 \mathrm{~A} \$ \mathrm{Ve}$ rticalStepDist_mm^2) $+0.00007 *(\mathrm{DB} 3 \mathrm{~A} \$$ Vertical StepDist_mm) +1.1579

11. HorizStepDist_mm_F $<-(-0.000009 *(\mathrm{DB} 3 \mathrm{~A} \$$ HorizStepDist_mm ^2) $)+(0.0017 *$ DB3A\$HorizStepDist_mm) +1.0098

12. PythagoreanStepDist_mm_F $<-(-0.002 *(\mathrm{DB} 3 \mathrm{~A} \$ \mathrm{Py}$ thagoreanStepDist_mm) $)+1.3779$

13. ManagementQualityIndex_F $<-(0.1082 *$ DB3A $\$ M a$ nagementQualityIndex) +0.8311

14. TrainSteps_binary_F $<-\left(-0.3245^{*}\right.$ DB3A $\$$ TrainSte ps_binary) +1.1239

15. DoorsPerCar_F $<-(0.2262 *$ DB3A\$DoorsPerCar $)+$ 0.4258

16. InterDoorDistance_m_F $<-(-0.035 * \mathrm{DB} 3 \mathrm{~A} \$$ Inter DoorDistance_m $)+1.3664$

17. DoorWidth_step_function_F $<-(0.2641 *$ DB3A $\$$ Door Width_step function) +0.4381

18. StandbackWidth_step_function_F $<-(0.0461 *(\mathrm{DB} 3 \mathrm{~A} \$$ StandbackWidth_step function) $)+0.9858$

19. VestibuleSize_m2_F $<-(-0.0622 *(\mathrm{DB} 3 \mathrm{~A} \$$ VestibuleSize_m2^2) $+(0.6823 *$ DB3A $\$$ VestibuleSize_m2) -0.6641

20. VestibuleCapacity_pass_F $<-(-0.0012 *(\mathrm{DB} 3 \mathrm{~A} \$ \mathrm{Ves}$ tibuleCapacity_pass^2) $)+(0.0883 *$ DB3A $\$$ Vestib uleCapacity_pass) -0.2796 
21. AisleWidthAtVestibule_F<- $((0.3772 * \mathrm{DB} 3 \mathrm{~A}$ \$Aisle WidthAtVestibule $)+0.6828$

22. AisleWidthNetOfPeopleFeet_m_F $<-(0.5107 * \mathrm{DB}$ 3A \$AisleWidthNetOfPeopleFeet_m) + 0.6056

23. SaloonExitDifficulty_F $<-(-0.0004 *(\mathrm{DB} 3 \mathrm{~A} \$$ Saloon

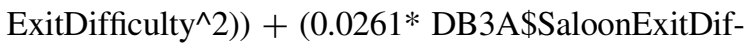
ficulty) +0.8255

24. CarAreaVsDoorWidth_m_F $<-(-0.0167 *$ DB3A\$CarAreaVsDoorWidth_m) +1.3768

25. SeatsPerCar_F $<-(-0.0044 *$ DB3A $\$$ SeatsPerCar $)$ $+1.3076$

26. PercentageOfSeatsLongitudinal_F $<-\left(0.0045^{*} \mathrm{DB} 3 \mathrm{~A}\right.$ \$PercentageOfSeatsLongitudinal $)+0.8793$

27. NoOfSeatsPerTrainWidth_F $<-(-0.1447 *$ DB3A $\$$ No OfSeatsPerTrainWidth) +1.5702

28. SeatingDensity_seats_per_m2_F $<-(-\quad 0.7346 * \mathrm{DB} 3 \mathrm{~A}$ \$SeatingDensity_seats_per_m2) +1.7735

Boarders:

1. NumberOfBoarders_F $<-0.5543 *(\mathrm{DB} 3 \mathrm{~B} \$$ NumberO fBoarders ${ }^{\wedge} 0.2397$ )

2. A_X_B_F $<-0.6571 *\left(\mathrm{DB} 3 \mathrm{~B} \$ \mathrm{~A} \_\mathrm{X} \_\mathrm{B}^{\wedge} 0.0916\right)$

3. VestibuleLoad_pass_F $<-((-0.0009) *(\mathrm{DB} 3 \mathrm{~B} \$$ Vest ibuleLoad_pass^2) $)+(0.0337 *$ DB3B \$Vestibule Load_pass) +0.9277

4. VestibuleLoadVsCapacity_F $<-((-0.9739) *(\mathrm{DB} 3 \mathrm{~B}$ \$VestibuleLoadVsCapacity^2) $)+(0.9093 *$ DB3B\$ VestibuleLoadVsCapacity) +0.9326

5. Boarders_in_xs_of_remaining_vest_cap_F $<-((-0.00$ $04) *\left(D B 3 B\right.$ \$Boarders_in_xs_of_remaining_vest_cap ${ }^{\wedge}$ $2))+(0.0311 *$ DB3B $\$$ Boarders_in_xs_of_remaining vest_cap) +0.716

6. PercentageWithLuggage_F $<-\quad(1.2465 *(\mathrm{DB} 3 \mathrm{~B} \$$ PercentageWithLuggage $\left.^{\wedge}(-0.179)\right)$

7. OutsideUnprotectedDummy_F $<-((-0.3782) *(\mathrm{DB} 3$ B \$OutsideUnprotectedDummy)) + 1.1067

8. PlatformWidth_m_F $<-\quad(0.0982 *$ DB3B\$PlatformWid th_m) +0.668

9. AveEgressDist_m_F $<-((-0.0024) *(\mathrm{DB} 3 \mathrm{~B} \$$ AveEgressDist_m) $)+1.1281$

10. VerticalStepDist_mm_F $<-((-0.0017) *(\mathrm{DB} 3 \mathrm{~B} \$$ Verti calStepDist_mm) $)+1.1709$

11. HorizStepDist_mm_F $<-((-0.0013) *(\mathrm{DB} 3 \mathrm{~B} \$$ Horiz StepDist_mm)) +1.1335

12. PythagoreanStepDist_mm_F $<-((-0.0023) *(\mathrm{DB} 3 \mathrm{~B}$ \$PythagoreanStepDist_mm) $)+1.3646$

13. ManagementQualityIndex_F $<-(0.0762 * \mathrm{DB} 3 \mathrm{~B} \$ \mathrm{Man}$ agementQualityIndex $)+0.8492$

14. TrainSteps_binary_F $<-\quad((-0.4278) *(\mathrm{DB} 3 \mathrm{~B} \$$ Train Steps_binary) $)+1.0967$
15. DoorsPerCar_F $<-(0.1259 * \mathrm{DB} 3 \mathrm{~B} \$$ DoorsPerCar $)+$ 0.6495

16. InterDoorDistance_m_F $<-((-0.0355) *(\mathrm{DB} 3 \mathrm{~B} \$ \mathrm{In}-$ terDoorDistance_m) $)+1.3162$

17. DoorWidth_step_function_F $<-(0.281 * \mathrm{DB} 3 \mathrm{~B} \$$ Door Width_step_function) +0.3515

18. StandbackWidth_step_function_F $<-\quad(0.138 * \mathrm{DB} 3$ B\$StandbackWidth_step_function) +0.8003

19. VestibuleSize_m2_F $<-((-0.0514) *(\mathrm{DB} 3 \mathrm{~B} \$$ Vesti buleSize_m2^2) $)+(0.6153 *$ DB3B $\$$ VestibuleSize_ m2) -0.6457

20. VestibuleCapacity_pass_F $<-((-0.001) *(\mathrm{DB} 3 \mathrm{~B} \$ \mathrm{Ve}$ stibuleCapacity_pass $\left.\left.{ }^{\wedge} 2\right)\right)+(0.0783 * \mathrm{DB} 3 \mathrm{~B} \$$ Vest ibuleCapacity_pass) -0.2152

21. AisleWidthAtVestibule_F<- $(0.3449 *$ DB3B $\$$ AisleWidthAtVestibule) +0.6691

22. AisleWidthNetOfPeopleFeet_m_F $<-(0.472 *$ DB3B $\$$ AisleWidthNetOfPeopleFeet_m) +0.5909

23. SaloonExitDifficulty_F $<-((-0.0002) *(\mathrm{DB} 3 \mathrm{~B} \$$ Salo onExitDifficulty $\left.\left.{ }^{\wedge} 2\right)\right)+(0.0151 * \mathrm{DB} 3 \mathrm{~B} \$$ SaloonExit Difficulty) +0.8495

24. CarAreaVsDoorWidth_m_F $<-((-0.0182) *(\mathrm{DB} 3 \mathrm{~B}$ \$CarAreaVsDoorWidth_m) $)+1.3568$

25. SeatsPerCar_F $<-((-0.0055) *(\mathrm{DB} 3 \mathrm{~B} \$$ SeatsPerCar $))+$ 1.3216

26. PercentageOfSeatsLongitudinal_F $<-(0.0042 * \mathrm{DB} 3$ $\mathrm{B} \$$ PercentageOfSeatsLongitudinal $)+0.8477$

27. NoOfSeatsPerTrainWidth_F $<-\left((-0.1456)^{*}\right.$ (DB3B \$NoOfSeatsPerTrainWidth) $)+1.5254$

28. SeatingDensity_seats_per_m2_F $<-((-0.6098) *(\mathrm{DB} 3$ B\$SeatingDensity_seats_per_m2) +1.6017

Supplementary InformationThe online version contains supplementary material available at https://doi.org/10.1007/s40864021-00161-8.

Acknowledgements Thanks are due to colleagues Alexander Barron of Imperial College and Jide Ehizele of the Railway Consultancy for helping with surveys, suggesting variables of interest, and commenting on earlier drafts of this paper.

Author Contributions Nigel G Harris compiled the literature review and wrote the paper. Flavia de Simone undertook the statistical analysis. Ben Condry provided some of the underlying hypotheses to test, and undertook internal peer review.

Funding The research underlying this paper was entirely funded inhouse by the Railway Consultancy and the Transport Strategy Centre at Imperial College.

Availability of Data and Materials The majority of data sets used in this research were collected in the process of commercial benchmarking and consultancy contracts for railway and metro companies, so are commercial-in-confidence. However, we have prepared a data paper containing more details than are summarised here. 


\section{Declarations}

Conflict of interest The authors are not aware of any competing interests relevant to this research.

Open Access This article is licensed under a Creative Commons Attribution 4.0 International License, which permits use, sharing, adaptation, distribution and reproduction in any medium or format, as long as you give appropriate credit to the original author(s) and the source, provide a link to the Creative Commons licence, and indicate if changes were made. The images or other third party material in this article are included in the article's Creative Commons licence, unless indicated otherwise in a credit line to the material. If material is not included in the article's Creative Commons licence and your intended use is not permitted by statutory regulation or exceeds the permitted use, you will need to obtain permission directly from the copyright holder. To view a copy of this licence, visit http://creativecommons. org/licenses/by/4.0/.

\section{References}

1. Alvarez AB, Merchan F, Poyo FJC, George RJC (2015) A fuzzy logic-based approach for estimation of dwelling times at Panama Metro stations. Entropy 17:2688-2705

2. d'Acierno L, Botte M, Placido A, Caropreso C, Montella B (2017) Methodology for determining Dwell times consistent with passenger flows in the case of metro services. Urban Rail Transit 3(2):73-89. https://doi.org/10.1007/s40864-017-0062-4

3. Antognoli M, Ricci S, Rizzetto L (2017) Effects of passengers' flows on regularity of metro service. Urban Transp. https://doi. org/10.2495/TDI-V2-N1-1-10

4. Buchmüller S, Weidmann U, Nash CA (2006) Development of a Dwell time calculation model for timetable planning. COMPRAIL XI, pp 525-534

5. Canavan S (2019) Best practices in operating high-frequency metro services. Transp Res Rec. https://doi.org/10.1177/ 0361198119845356

6. Christoforou Z, Chandakas E, Kaparias I (2020) Investigating the impact of Dwell time on the reliability of urban light rail operations. Urban Rail Transp. https://doi.org/10.1007/s40864-02000128-1

7. Coxon S, Burns K, de Bono A, Napper R (2011) An examination of three approaches to metro rolling stock design. Aus Transp Res Forum Proc

8. Daamen W, Lee Y-C, Wiggenraad P (2008) Boarding and alighting experiments. Transp Res Rec 2042:71-81. https://doi. org/10.3141/2042-08

9. Dirmeier W (1978) Die Bedeutung der Haltezeit im Stadtschellbahnbetrieb. ETR 27(5):273-276

10. Fernandez R (2011) Experimental study of bus boarding and alighting times. In: European transport conference proceedings

11. Fernandez R, Valencia A, Seriani S (2015) On passenger saturation flow in public transport doors. Transp Res A 78:102-112

12. Fox $C$ et al (2017) Understanding users' behaviours in relation to concentrated boarding. In: Conference paper available at https:// doi.org/10.3233/978-1-61499-792-4-120

13. Fruin JJ(1971) Pedestrian planning and design (206pp)

14. Girnau G, Blennemann F (1970) Verknüpfung von Nahverkehrssysteme, Düsseldorf

15. Harris NG (2006) Train boarding and alighting rates at high passenger loads. J Adv Transp 40(3):249-263

16. Harris NG (2019) Managing station stops. In: Connor P et al (eds) Designing and managing urban railways, vol 7. University of Birmingham/A \& N Harris, pp 87-100 (391pp)
17. Harris NG, Anderson RJ (2007) An international comparison of urban rail boarding and alighting rates. J Rail Rapid Transit 221(F4):521-526

18. Harris NG, Ehizele J (2019) The impact of luggage on passenger boarding and alighting rates. In: International railway symposium, Aachen, 28th November

19. Harris NG, Graham DJ, Anderson R, Li J (2014a) The impact of urban rail boarding and alighting factors. In: TRB 93rd annual meeting, Washington, USA

20. Harris NG, Risan $\varnothing$, Schrader S-J (2014b) The impact of differing door widths on passenger movement rates. In: COMPRAIL 14 Special contributions, Rome, pp 53-64

21. Heinz W (2003) Passenger service times on trains-theory, measurements and models. PhD thesis, Royal Institute of Technology, Stockholm

22. Holloway C, Thoreau T, Roan T-R et al (2015) Effect of vertical step height on boarding and alighting time of train passengers. Proc Inst Mech Eng Part F J Rail Rapid Transit 230(4):1234-1241

23. Kuipers RA, Palmqvist C-W, Olssson NOE, Hiselius LW (2021) The passengers' influence on Dwell times at station platforms: a literature review. Transp Rev. https://doi.org/10.1080/01441647. 2021.1887960

24. Lam WHK, Cheung CY, Poon YF (1998) A study of train Dwelling time at the Hong Kong mass transit railway system. J Adv Transp 32(3):285-296

25. Lee J, Yoo S, Kim H, Chung Y (2018) The spatial and temporal variation in passenger service rate and its impact on train dwell time. Int J Sustain Transp. https://doi.org/10.1080/15568318. 2018.1432731

26. Li D et al (2018) Testing the generality of a passenger disregarded train dwell time estimation model at short stops. J Adv Transp. https://doi.org/10.1155/2018/8521576

27. Luangloriboon N, Seriani S, Fujiyama T (2020) The influence of the density inside a train carriage on passenger boarding rate. Int $\mathrm{J}$ Rail Transp. https://doi.org/10.1080/23248378.2020.1846633

28. Oliveira LCR et al (2019) Analysing passengers' behaviours when boarding trains. Robotics Comput Int Manuf 57:282-291

29. Palmqvist C-W, Tomii N, Ochiai Y (2020) Explaining dwell time delays with passenger counts for some commuter trains in Stockholm and Tokyo. J Rail Transp Plan Man. https://doi.org/ 10.1016/j.jrtpm.2020.100189

30. Railway Consultancy Ltd (1996) The impact of stepping distances on train boarding and alighting times. Report for Crossrail

31. Rodriguez GDA, Seriani S, Holloway C (2016) "Impact of platform edge doors on passengers' boarding and alighting time and platform behavior. Transp Res Rec J Transp Res Board 2540:102-110

32. RSSB (2015) Platform train interface strategy. London

33. Seriani S, Fernandez R, Luangboriboon N, Fujiyama T (2019) Exploring the effect of boarding and alighting ratio on passengers' behaviour at metro stations by laboratory experiments. J Adv Transp. https://doi.org/10.1155/2019/6530897

34. Seriani S, Fujiyama T (2019) Exploring the effect of train design features on the boarding and alighting time by laboratory experiments. Collect Dyn 4(A22):1-21. https://doi.org/10.17815/ CD. 2019.22

35. Seriani S, Fernandez R, Oyanedel C (2021) The impact of gap dimensions on passengers boarding and alighting using different mobility aids. Int J Rail Transp 9(2):186-202. https://doi.org/10. 1080/23248378.2020.1836685

36. Thoreau $\mathrm{R}$ et al (2017) Train design features affecting boarding and alighting. J Adv Transp. https://doi.org/10.1002/atr.1446

37. Transportation Research Board (1996) Rail transit capacity. TCRP Report 13, Washington 
38. Watts D et al (2016) Passenger boarding time, mobility and dwell time for high speed 2

39. Weidmann U (1994) Der Fahrgastwechsel im öffentlichen Personenverkehr. IVT 99, ETH, Zürich

40. Weidmann U (1995) Grundlagen zur Berechnung der Fahrgastwechselzeit. IVT 105, ETH, Zürich
41. Weston JG (1989) Train service model, technical guide. London Underground Operational Research note 89/18

42. Wiggenraad P (2001) Alighting and boarding times of passengers at Dutch railway stations. TRAIL Research School paper, December 